\title{
Moisture Pathways into the U.S. Intermountain West Associated with Heavy Winter Precipitation Events*
}

\author{
Michael A. AleXANDER \\ NOAA/Earth System Research Laboratory, Boulder, Colorado

\begin{abstract}
James D. Scott, Dustin Swales, Mimi Hughes, Kelly Mahoney, and Catherine A. Smith
NOAA/Earth System Research Laboratory, and Cooperative Institute for Research in Environmental Sciences, University of Colorado Boulder, Boulder, Colorado
\end{abstract}

(Manuscript received 15 July 2014, in final form 20 November 2014)

\begin{abstract}
Two methods were used to identify the paths of moisture transport that reach the U.S. Intermountain West (IMW) during heavy precipitation events in winter. In the first, the top 150 precipitation events at stations located within six regions in the IMW were identified, and then back trajectories were initiated at 6-h intervals on those days at the four Climate Forecast System Reanalysis grid points nearest the stations. The second method identified the leading patterns of integrated water vapor transport (IVT) using the three leading empirical orthogonal functions of IVT over land that were first normalized by the local standard deviation. The top $1 \%$ of the associated 6-hourly time series was used to construct composites of IVT, atmospheric circulation, and precipitation. The results from both methods indicate that moisture originating from the Pacific that leads to extreme precipitation in the IMW during winter takes distinct pathways and is influenced by gaps in the Cascades (Oregon-Washington), the Sierra Nevada (California), and Peninsular Ranges (from Southern California through Baja California). The moisture transported along these routes appears to be the primary source for heavy precipitation for the mountain ranges in the IMW. The synoptic conditions associated with the dominant IVT patterns include a trough-ridge couplet at $500 \mathrm{hPa}$, with the trough located northwest of the ridge where the associated circulation funnels moisture from the west-southwest through the mountain gaps and into the IMW.
\end{abstract}

\section{Introduction}

While generally dry, the interior of the western United States can experience extreme precipitation events. For example, in early November 2006, a major rain and flood event occurred in portions of western Montana. One weather station in Glacier National Park recorded over $300 \mathrm{~mm}$ (12 in.) of precipitation between 3 and 8 November and the flow in the North Fork of the Flathead River reached $510 \mathrm{~m}^{3} \mathrm{~s}^{-1}\left(18000 \mathrm{ft}^{3} \mathrm{~s}^{-1}\right)$ on 8 November, exceeding the previous November record

\footnotetext{
* Supplemental information related to this paper is available at the Journals Online website: http://dx.doi.org/10.1175/JHM-D-14-0139.s1.

Corresponding author address: Michael Alexander, NOAA/Earth System Research Laboratory, R/PSD1, 325 Broadway, Boulder, CO 80305.

E-mail: michael.alexander@noaa.gov
}

by $\sim 40 \%$ (Bernhardt 2006; Neiman et al. 2008). Extreme precipitation events can also occur over the southwestern United States during winter; for example, in late January 2010, a series of three strong storms caused record precipitation and widespread flooding in central Arizona. How does the moisture penetrate the high terrain and complex topography near the U.S. West Coast in sufficient amounts to produce extreme precipitation events in the Intermountain West (IMW)? Since flow over a mountain causes air to cool and thus hold less moisture, air parcels likely take unique pathways through mountain gaps and/or have multiple moisture sources in order to retain enough water vapor to produce intense winter precipitation events in states such as Arizona, Colorado, Idaho, and Utah.

Extreme precipitation events can cause severe flooding, potentially leading to safety and infrastructure problems. Determining how these events occur in the IMW (taken here to be between the Sierra Nevada-Cascade

DOI: 10.1175/JHM-D-14-0139.1 
Range and the Continental Divide) would help water managers and emergency planners better prepare for these extreme precipitation events. For example, the Bureau of Reclamation operates hundreds of dams in the IMW, and a detailed understanding of the sources of moisture and processes leading to heavy precipitation would inform decisions about dam safety and flood hydrology.

Long narrow bands of enhanced water vapor transport generally located ahead of cold fronts, termed atmospheric rivers (ARs; Newell et al. 1992; Zhu and Newell 1998), are associated with heavy rain and snow events along the U.S. West Coast (Ralph et al. 2004, 2006; Neiman et al. 2002, 2008, 2011; Ralph and Dettinger 2011). Observational studies of strong winter storms over California led to the identification of key ingredients for heavy precipitation in the Coast Range and the Sierra Nevada, including an AR transporting warm and moist air from the subtropical Pacific (known colloquially as the "Pineapple Express"; McGuirk et al. 1987, 1988; Lackmann and Gyakum 1999), upslope flow with the atmospheric moisture transport being perpendicular to the topography, a landfalling low-level jet, low static stability, and strong upper-level dynamics (Pandey et al. 1999; Neiman et al. 2002; O'Hara et al. 2009). Farther inland, the structure and evolution of storms and their associated precipitation are greatly altered by upstream mountain ranges, such as the Cascades and the Sierra Nevada. For example, the classical model of an extratropical cyclone with strong near-surface fronts often fails in the IMW, where many storms only have elevated baroclinic zones (Marwitz 1980; Schultz et al. 2002).

Recent studies indicate that ARs could move inland and contribute a significant fraction $(10 \%-50 \%)$ of wintertime precipitation in the IMW (Leung and Qian 2009; Dettinger et al. 2011; Rutz and Steenburgh 2012). Some pathways for inland ARs have been identified. Rutz and Steenburgh (2012) found that ARs that traverse Baja California contribute significantly to precipitation in Arizona, exemplified by the extreme precipitation-flooding event that occurred in Arizona in January 2010 (described above) that penetrated through gaps in the mountains along the Baja Peninsula (Neiman et al. 2013; Hughes et al. 2014). Using combined empirical orthogonal functions (EOFs) of zonal and meridional integrated water vapor transport (IVT), Rivera et al. (2014) identified two AR patterns that cause heavy winter precipitation in the Verde River basin in central Arizona: one originates near Hawaii and crosses central Baja California mainly from the west before turning north, and the second originates in the eastern tropical Pacific and crosses southern Baja
California from the southwest. Rutz et al. (2014) found that ARs could penetrate into portions of the Northwest and Southwest United States, including central Arizona, but appeared to be blocked by the high Sierra Nevada in California. The Great Salt Lake can also act as a regional source of moisture for heavy precipitation in northern Utah (Steenburgh et al. 2000; Steenburgh 2003). While the aforementioned studies have identified some of the moisture sources for the IMW, the moisture pathways leading to heavy precipitation in the IMW during winter have not been examined systematically.

Air parcel trajectories have been used to identify the sources and transport of moisture, including those associated with ARs. Knippertz and Wernli (2010) developed a climatology of tropical-to-extratropical trajectories of moist air that identified the Pineapple Express as one of the four main pathways, although the trajectories with strong moisture transport that reach the coast of western North America may also have midlatitude origins (Roberge et al. 2009; Neiman et al. 2013). Using air parcel movements calculated backward in time, or back trajectories, Bao et al. (2006) found that while some of the moisture within ARs that reached the U.S. West Coast originated in the tropics, much of it resulted from evaporation and moisture convergence in midlatitudes in the warm sector of extratropical cyclones. Back trajectories have also proved useful in understanding precipitation processes and diagnosing moisture sources in other mountainous areas, including the Appalachian Mountains (Konrad 1994; Perry et al. 2007; Fuhrmann and Konrad 2013).

Here, we investigate the following questions associated with extreme precipitation events in the IMW during the cold season (October-March).

- Are there dominant moisture pathways?

- Do they differ for different regions in the IMW?

- Does much of the moisture transport occur through gaps in the mountains, or can moisture remain in the atmosphere after passing over higher topography?

- What synoptic features are associated with the moisture transport?

We will address these questions using two complementary methods: air parcel trajectories provide a Lagrangian approach for identifying regional pathways into the IMW, while EOF/principal component (PC) analyses of IVT provide a large-scale Eulerian view of the dominant moisture pathways and the associated synoptic conditions. The precipitation data and atmospheric reanalysis used in this study are described in section 2 along with methods used to compute trajectories and EOFs/PCs. The results are presented in section 3 and summarized and discussed in section 4 . 


\section{Data and methods}

We use a combination of datasets and methods to identify the moisture pathways and synoptic conditions associated with heavy winter precipitation events in the IMW during 1979-2010, the period when highresolution atmospheric reanalysis is available.

\section{a. Station precipitation data}

We obtained daily precipitation data from the Global Historical Climatology Network (http://www.ncdc.noaa. gov/oa/climate/ghen-daily/; Durre et al. 2008, 2010; Menne et al. 2012) to identify heavy precipitation events. We only included stations that had more than 20 years of data, where less than $20 \%$ of the days were missing observations during 1979-2011, to ensure a reasonable climatology at each station. The stations were grouped into six regions covering most of the IMW, including 1) eastern Washington, northern Idaho, and southeastern British Columbia (hereafter WA-nID); 2) eastern Oregon and southern Idaho (OR-sID); 3) Nevada (NV); 4) Utah and western Colorado (UT$\mathrm{CO})$; 5) southeastern California, western Arizona, and southern Nevada (sCA); and 6) Arizona and New Mexico (AZ-NM; Fig. 1). While the choice of regions is subjective, their number and boundaries were based on a number of considerations, including: 1 ) that regions have more than 50 stations (and all but NV and sCA have more than 100); 2) the location of topographic features, for example, selecting mountain chains for some of the regional boundaries; 3 ) grouping stations that exhibited similar absolute or relative precipitation maxima, for example, many of the stations in the sCA region exhibited daily precipitation maxima that had a relatively small magnitude but made a substantial contribution to the annual precipitation; and 4) the regions with IVT maxima based on the EOF analysis (see section $3 \mathrm{~b}$ ).

To focus on the heaviest events in our record, we first identified the 150 maximum 1-day precipitation amounts during $1979-2011$ ( $\sim 2.5 \%$ of winter days) at stations within each of the six regions shown in Fig. 1. The precipitation events are independent in that only the station with the maximum on that day is included. The 150 maximum 1-day precipitation values within a region are shown in Fig. 2a via color shading (stations included in the analysis but without a top event are shown by open circles; some stations recorded more than one event). The precipitation amounts over the IMW range from approximately 25 to $175 \mathrm{~mm}$, with all regions except NV having at least one station with more than $100 \mathrm{~mm}$. The greatest 1-day totals $(>125 \mathrm{~mm})$ are found in the central WA-nID, central OR-sID, northern sCA, and western AZ-NM regions.

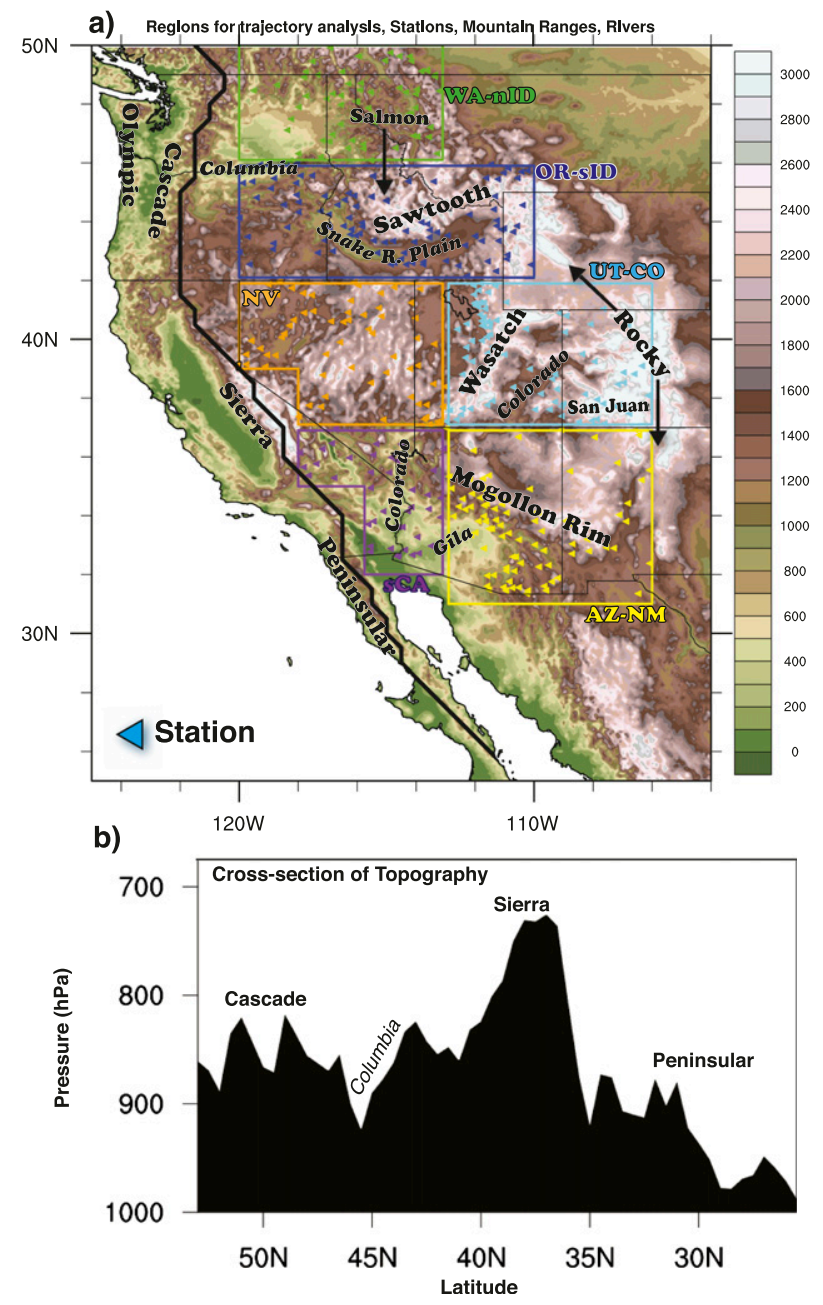

FIG. 1. (a) Topographic map ( $\mathrm{m}$; shading) of the western United States and northern Mexico, that shows the six regions (colored text) used to compute the back trajectories: WA-nID (green), ORsID (dark blue), NV (orange), UT-CO (light blue), sCA (purple), and AZ-NM (yellow). Mountain ranges are in black, with the major ranges of the Cascades, the Sierra Nevada, and the Rocky Mountains in larger font. River valleys are in italics, and station locations are indicated by triangles with the color of their respective region. The black curve, extending along the crest of the Cascades, the Sierra Nevada, and the Peninsular Ranges, indicates the position of the cross section shown in Figs. 4-7 (and Figs. SM8 and SM9 in the supplemental materials). (b) Cross section of the topography $(\mathrm{hPa})$ along the black curve shown in (a).

The percentage of the top 150 events occurring at a particular station in each of the regions is shown in Fig. 2b. Less than $5 \%$ of the events occur at most stations in all six regions in the domain. However, the extreme events are not uniformly distributed across a given region: many stations do not have a precipitation event in the top 150, but there are a few stations at which $10 \%$ or even $15 \%$ of the extremes occur. The concentration of extreme events at just a few stations is most pronounced 


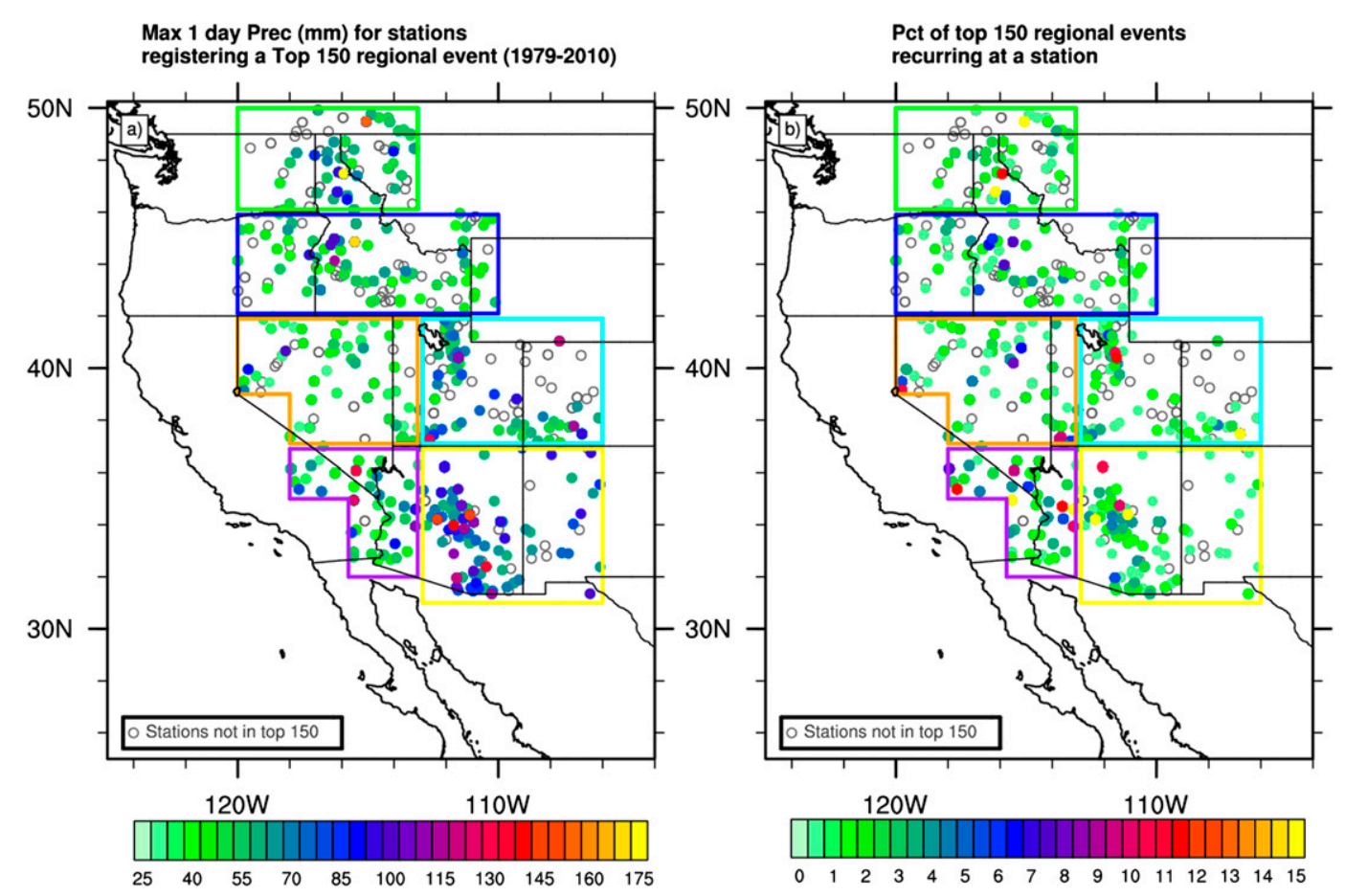

FIG. 2. (a) The 150 max 1-day precipitation amounts during 1979-2011 at stations within each of the six regions. Only the station with the max on a given day is included, although a station could have more than one event among the 150 cases. Open circles show stations without a top event. (b) Percentage of the top 150 events occurring at a particular station in each of the regions.

in the WA-nID, AZ-NM, and sCA regions, where only three stations account for $\sim 40 \%$ of the cases. While only using the station with the maximum precipitation on a given day focuses the analyses on subareas within a region, likely the windward side of mountain ranges, it allows us to 1) have the same number of cases in each region; 2) concentrate on events that are most likely to cause damage by flooding; and 3) obtain the main trajectory paths associated with the synoptic-scale circulation in winter storms, which would be similar for stations separated by a few hundred kilometers (although extreme precipitation likely depends on the local winds, topography, and mesoscale dynamics).

\section{b. CFSR}

The primary source for the gridded atmospheric fields used here is the Climate Forecast System Reanalysis (CFSR; Saha et al. 2010) from the National Centers for Environmental Prediction (NCEP). The CFSR is global and includes atmosphere, ocean, land and sea ice models, and an assimilation system to merge the model first-guess fields with observations. The resolution of the spectral atmospheric model is T382 $(\sim 40 \mathrm{~km})$ with 64 vertical levels. The CFSR fields are archived on a $0.5^{\circ}$ latitude and longitude grid at 6-h intervals from January 1979 to March 2011.
In the CFSR, narrow breaks in the mountains are not fully resolved and the height of the actual mountain tops is much lower than in nature; thus, "gaps" are taken here to include the atmosphere above local minima in the reanalysis topography and along steep mountain slopes, such as the northern side of the Sierra Nevada. Additionally, the impact of mountain gaps on the atmosphere extends into the free troposphere (Gaberšek and Durran 2006).

\section{c. Livneh precipitation data}

We also use gridded precipitation values from a highresolution $\left(1 / 16^{\circ}\right)$ dataset recently developed by Livneh et al. (2013) available over the conterminous United States and the Columbia River watershed in southwestern Canada for the years 1915-2011. It is an updated version of the Maurer et al. (2002) dataset and is derived using daily observations from approximately 20000 NOAA Cooperative Observer stations. The daily data are rescaled so that the long-term monthly climatology equals that from the Parameter-Elevation Relationships on Independent Slopes Model (PRISM; Daly et al. 1994). The Livneh dataset likely provides a better representation of precipitation than the CFSR in the IMW because of its higher resolution and explicit treatment of topography. 


\section{d. Trajectories}

Backward (in time) air parcel trajectories, based on the three-dimensional wind field obtained from the CFSR, were computed using a method originally developed at the University of Melbourne (http://www. cycstats.org/trajectories/trajhome.htm; Noone and Simmonds 1999; Barras and Simmonds 2009), which we modified to provide additional output, including the surface pressure. Trajectories were computed for the top 150 1-day precipitation totals (as defined in section 2a) that occurred at stations within each of the six regions shown in Figs. 1 and 2. The trajectories were initiated from the four CFSR grid points surrounding the station that recorded the extreme precipitation event and were initiated at the four 6-h intervals on the day the event occurred. In the vertical, we examined trajectories initiated on pressure levels from $600 \mathrm{hPa}$ down to the surface at $50-\mathrm{hPa}$ increments $(600,650,700$, etc. $)$. For the results presented here, we used trajectories starting at a single pressure level located between 50 and $100 \mathrm{hPa}$ above (at a lower pressure than) the surface. For example, if the surface pressure was $827 \mathrm{hPa}$, trajectories were initiated at the 750-hPa level. We chose this level, which is generally located in the upper boundary layer/lower free troposphere, because it was high enough so that nearly all $(>99 \%)$ of the trajectories remained above the surface over North America but was low enough to be located within the region of strong water vapor transport (see, e.g., Neiman et al. 2013; Rivera et al. 2014). A total of 2400 trajectories (150 independent events $\times 4$ CFSR grid points $\times 4$ times per day) were initiated in each region. The position of a trajectory is computed backward in time over the five previous days at 1 -h intervals using the 6-hourly threedimensional CFSR wind fields.

The results from the trajectory analysis will be influenced by several factors, including the location of stations within a region and the frequency with which they get heavy precipitation. The individual trajectories will also be influenced by the resolution of the CFSR, which is relatively fine compared to most reanalyses, but is still coarse $(\sim 40 \mathrm{~km})$ relative to the topographic features in the western United States. The trajectories are also not tracking moisture directly but represent air parcels initially located near the station recording heavy precipitation; it is possible that some trajectories track a drier sector of a given storm.

\section{e. EOFs of IVT}

We also examine moisture pathways and associated synoptic variability using EOFs of the IVT. The IVT was derived from CFSR winds $\mathbf{V}$ and specific humidity $q$ on mandatory pressure levels that were vertically integrated from the surface to $300 \mathrm{hPa}\left(\sum_{P_{300 \mathrm{hPa}}}^{P_{\text {sc }}} \mathbf{V} q \Delta p / g\right)$. The IVT was computed at 6-h intervals during winter (October-March) from 1979 to 2011. The mean and standard deviation of IVT over the domain $\left(25^{\circ}-60^{\circ} \mathrm{N}\right.$, $150^{\circ}-105^{\circ} \mathrm{W}$ ) both exhibit a maximum at $\sim 40^{\circ} \mathrm{N}, 145^{\circ} \mathrm{W}$ over the Pacific that extends northeastward toward the northwestern United States (Fig. SM1 in the supplemental materials). Given that IVT variability is greater over the Pacific and along the U.S. West Coast than in the IMW, we took several steps to highlight IVT patterns in the IMW prior to calculating the EOFs. First, IVT anomalies were computed by subtracting the monthly means from the total field and were then normalized by dividing the anomaly values by the standard deviation of the 6-hourly data over all years in a given calendar month. Finally, the EOFs were computed using only land points. We examine the three leading EOFs and use their associated PCs to identify when the patterns of IVT and other variables are of large amplitude.

\section{Results}

\section{a. Trajectory analysis}

To illustrate air parcel paths, example backward trajectories were initiated on four different days at the four CFSR grid points surrounding stations that recorded heavy precipitation in the OR-sID region (Fig. 3). While all of the trajectories came from the Pacific, they indicate that moist air parcels can still take diverse routes to reach the lower troposphere over southwestern Idaho, including central and Northern California, Nevada, and Oregon (Fig. 3a); central Oregon (Figs. 3b,d); and Southern California and Nevada (Fig. 3c). Some of the trajectories indicate slower and/or more circuitous routes, for example, two loops over Northern California, while several others meander over the Snake River plain in southwestern Idaho for trajectories reaching southeastern Idaho on 20 November 2010 (Fig. 3d). All trajectory segments occur at pressures (color shading) greater than $700 \mathrm{hPa}$. The trajectories that pass through central Oregon remain at relatively low pressures (approximately $700-800 \mathrm{hPa}$; relatively high elevations) over the Cascade Range, while those that pass through northeastern California are located at higher pressures over California's Central Valley and remain at relatively high pressure $(>800 \mathrm{hPa}$ ) while passing north of the high Sierra Nevada. The trajectories for 11 March 1995 illustrate a different path: the trajectories come from the south and stay at relatively low pressure over land; they parallel the high narrow mountain ranges in Nevada and pass through a relatively low point in the mountains in Southern California, near $\sim 35^{\circ} \mathrm{N}, 117^{\circ} \mathrm{W}$. 

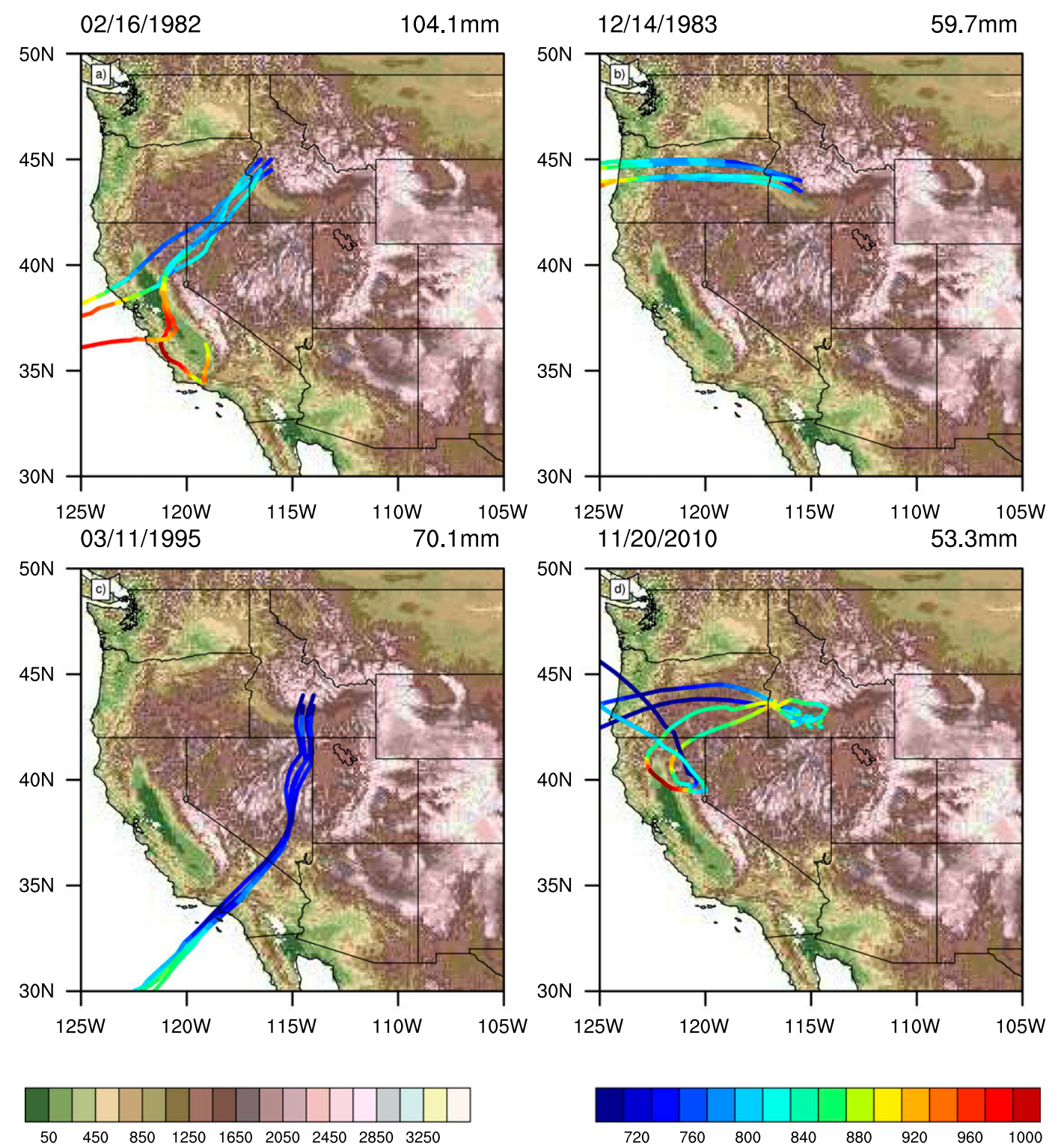

FIG. 3. Examples of backward trajectories that were initiated near the surface (surface pressure is $50 \mathrm{hPa}$ ) at the four CFSR grid points around the station at 0000 UTC on the day during which one of the top 150 precipitation events occurred in the OR-sID region. The dates and precipitation amounts are given above for the four cases. The pressure (hPa) along a trajectory segment is shown by the color (blue-red) scale on the lower right and the terrain height (m) by the (green-white) scale on the bottom left.

To determine if the air parcels leading to heavy precipitation have preferred routes, the number of hourlong trajectory segments that end within a CFSR grid volume are counted. The counts are performed for the back trajectories for the top 150 events (16 trajectories per event) initiated in each of the six regions and are presented as maps of the number of trajectory points throughout a given CFSR column and as cross sections of the number of counts as a function of height along a transect (indicated by the black line in Fig. 1) spanning the highest portions of the Cascades, the Sierra Nevada, and the Peninsular Ranges (north-south range extending from east of San Diego through Baja California).

Count maps and cross sections for the three northern regions (i.e., WA-nID, OR-sID, and NV) are presented in Fig. 4. Broadscale aspects of the topography are also shown on the maps. The count map for the WA-nID region (Fig. 4a) shows the greatest number of trajectory segments in northern Idaho and over southeastern Washington, which corresponds with the area where 

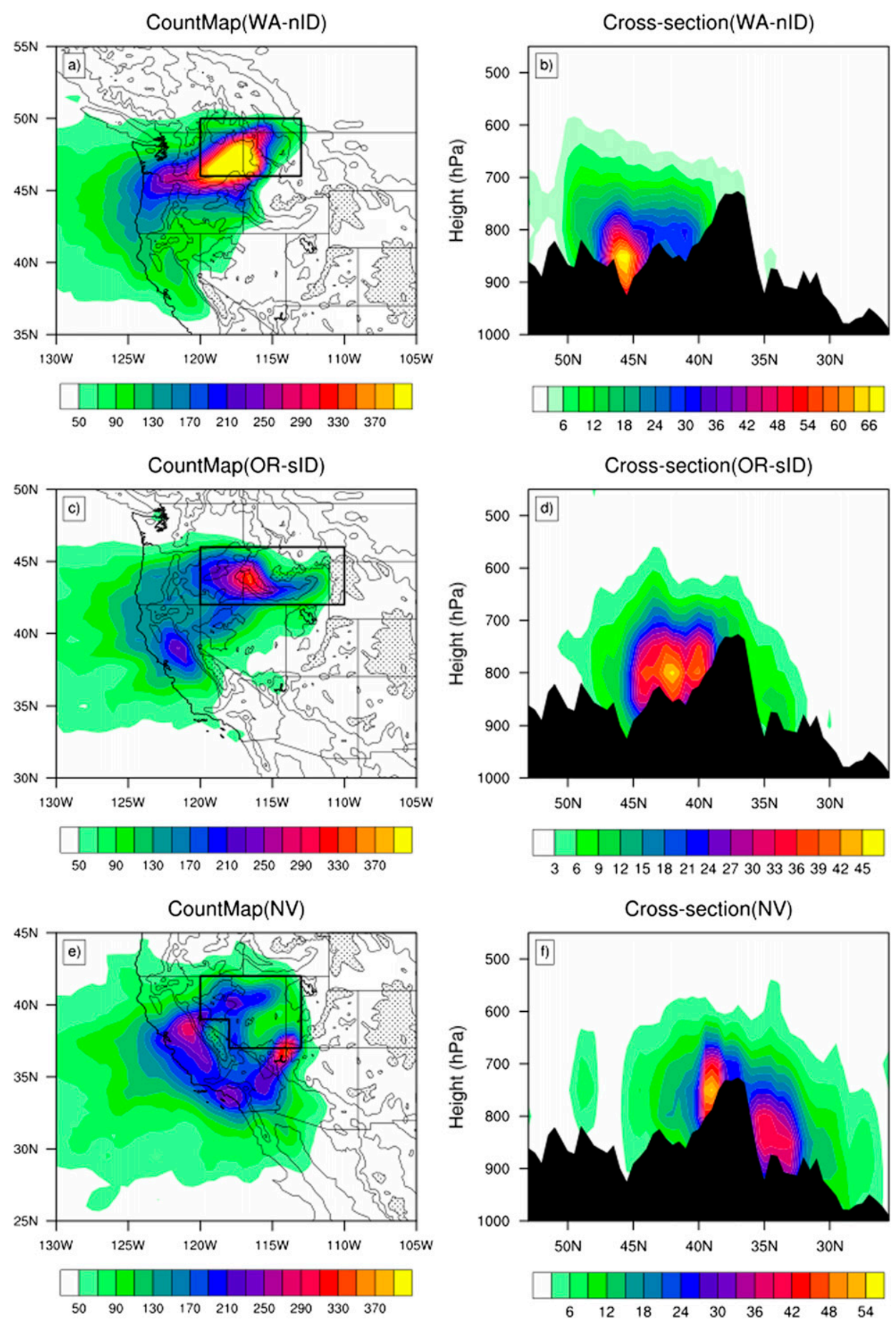

FIG. 4. (left) Count maps and (right) cross sections indicating the number of back trajectories that pass through a CFSR grid column originating in the (a),(b) WA-nID; (c),(d) OR-sID; and (e),(f) NV regions. The trajectories are initiated at 0000, 0600,1200, and 1800 UTC on days when one of the top 150 (independent) precipitation events occurred. The trajectories are initiated at the four CFSR grid points around the station that recorded the event at a single pressure level located between 50 and $100 \mathrm{hPa}$ above the surface (see text for more details). A total of 2400 trajectories were initiated in each region. The position of a trajectory is estimated at 1-h intervals over the five previous days using the 6-hourly 3D CFSR wind fields. Topography is depicted via a five-point smoother applied to the 30-arc-s $(\sim 1 \mathrm{~km})$ terrain height, with contours at $1000 \mathrm{~m}$ $(3281 \mathrm{ft}), 1500 \mathrm{~m}(4921 \mathrm{ft})$, and $2300 \mathrm{~m}(7546 \mathrm{ft})$ and stippling above $2300 \mathrm{~m}$. Vertical cross section of the backtrajectory counts along the crest of the Cascades, the Sierra Nevada, and the Peninsular Ranges (black curve in Fig. 1) for the WA-nID, OR-sID, and NV regions. The terrain is shown in black. 
backward trajectories are initiated (Fig. 2). Farther west, the axis of higher count values continues along the Washington-Oregon border, over northwestern Oregon and the Pacific. While the count map indicates that trajectories can occur across much of the northwestern United States from central California to the Canadian border (counts $>50$ ), the majority of the trajectories appear to move through the Columbia River gorge gap in the Cascade Range (as indicated by the break in the 1000 -m contours at $\sim 45.5^{\circ} \mathrm{N}, 122^{\circ} \mathrm{W}$ ) and continue along the Columbia River valley. Flow through this gorge is supported by the cross section of the number of trajectories originating in WA-nID, in that the greatest number of trajectories passes through the mountains below $800 \mathrm{hPa}$ at $45^{\circ} \mathrm{N}$ in the $\mathrm{v}$-shaped notch in the topography (Fig. 4b). A modest secondary maximum occurs in the trajectory counts over central California, which extends along the northern flank of the Sierra Nevada near $41^{\circ} \mathrm{N}$.

The count map and cross section for the OR-sID region, shown in Figs. $4 \mathrm{c}$ and $4 \mathrm{~d}$, show a very different pathway than the trajectories that impact northern Idaho. Along the coast the trajectories extend from the Oregon-Washington border to central California, but with a preferred path over the Sacramento Valley (northern portion of the Central Valley), across northeastern California and northwestern Nevada and into southern Washington and Idaho. The map and cross section for this region indicate that the trajectories pass to the north of the high Sierra Nevada, with the highest cross-sectional count density $\sim 50 \mathrm{hPa}$ above a local terrain minimum at $\sim 41^{\circ} \mathrm{N}$ near Burney, California, and over a lower-elevation portion of northwestern Nevada. Upon reaching Idaho, many trajectories follow the Snake River plain, which has a bow shape and extends across all of southern Idaho. The counts also suggest a secondary path over the Cascades and across Oregon.

The count map and cross section for the NV region (Figs. 4e,f) indicate that the highest portion of the Sierra Nevada, which extends along a northwest-southeast axis between about $35^{\circ}$ and $38^{\circ} \mathrm{N}$, is a barrier that most air parcels flow around. One trajectory path is just to the north of the high Sierra Nevada, with higher counts over north-central Nevada, while a second extends over Southern California and into southern Nevada. Downstream of the Sierra Nevada, there are a higher number of counts between the two branches, suggesting that the moisture flow may fill in on the leeward side of the mountains. The relatively high elevation (and low pressure) that the air parcels take to reach $\mathrm{NV}$, especially for the northern route, may limit the amount of moisture they carry and contribute to the lack of extreme precipitation in this region.
Maps and cross sections for the three southern regions, UT-CO, sCA, and AZ-NM, are shown in Fig. 5. For all three, the majority of the routes pass over the Pacific and into California or Baja California. The primary axis for the maximum trajectory counts for the UT-CO region (Fig. 5a) is similar to the southern branch for the NV region, that is, across Southern California and Nevada, but here it extends into western Utah along the western side of the Wasatch Range. A secondary area of high trajectory counts extends along the UtahArizona border, where the terrain is relatively low, and continues into southwestern Colorado, where there is another maximum near the San Juan Mountains. Some air parcels reaching UT-CO during heavy precipitation events enter the United States from the south, including the Gulf of California. The accompanying cross section (Fig. 5b) indicates that the highest number of trajectories pass south of the high Sierra Nevada at $\sim 35^{\circ} \mathrm{N}$ between 900 and $750 \mathrm{hPa}$ near a gap in the mountains.

The majority of the back trajectories in sCA were initiated and traverse the southern portion of the region (Fig. 5c), which they reach by either utilizing a zonal path near the border with Mexico or by crossing northern Baja California near $\sim 29^{\circ} \mathrm{N}$ and then going north over the Gulf of California. The accompanying cross section (Fig. 5d) indicates that both paths are influenced by mountain gaps where more trajectories pass through the northern gap.

The trajectory count maximum occurs in the western part of the AZ-NM region (Fig. 5e) in the vicinity of the Mogollon Rim, where many extreme precipitation events occurred. The pathways for the AZ-NM are similar to those for the sCA region, except that more trajectories utilize the southern gap at $\sim 29^{\circ} \mathrm{N}$ (Fig. 5f), which is wider and deeper than the one near the border.

Count maps of back trajectories over 6-h intervals ( 0 $6,6-12 \mathrm{~h}$, etc.) are shown for all six regions in the supplemental materials. Going forward in time, air parcels extending over a wide swath of the North Pacific propagate to the west-northwest and generally cross the western coast of North America 24-36h prior to reaching the target region (Figs. SM2-SM7 in the supplemental materials).

How unique are these pathways? That is, are the trajectories on all winter days in general similar to or different than those associated with extreme precipitation events? To address this question, we randomly selected days and locations (which could include those with extreme events) to initialize the back trajectories as follows: for each region, we determine the stations at which the top 150 events occurred, then randomly select one of these stations and a date between October and March from 1979 to 2011 using a random number 

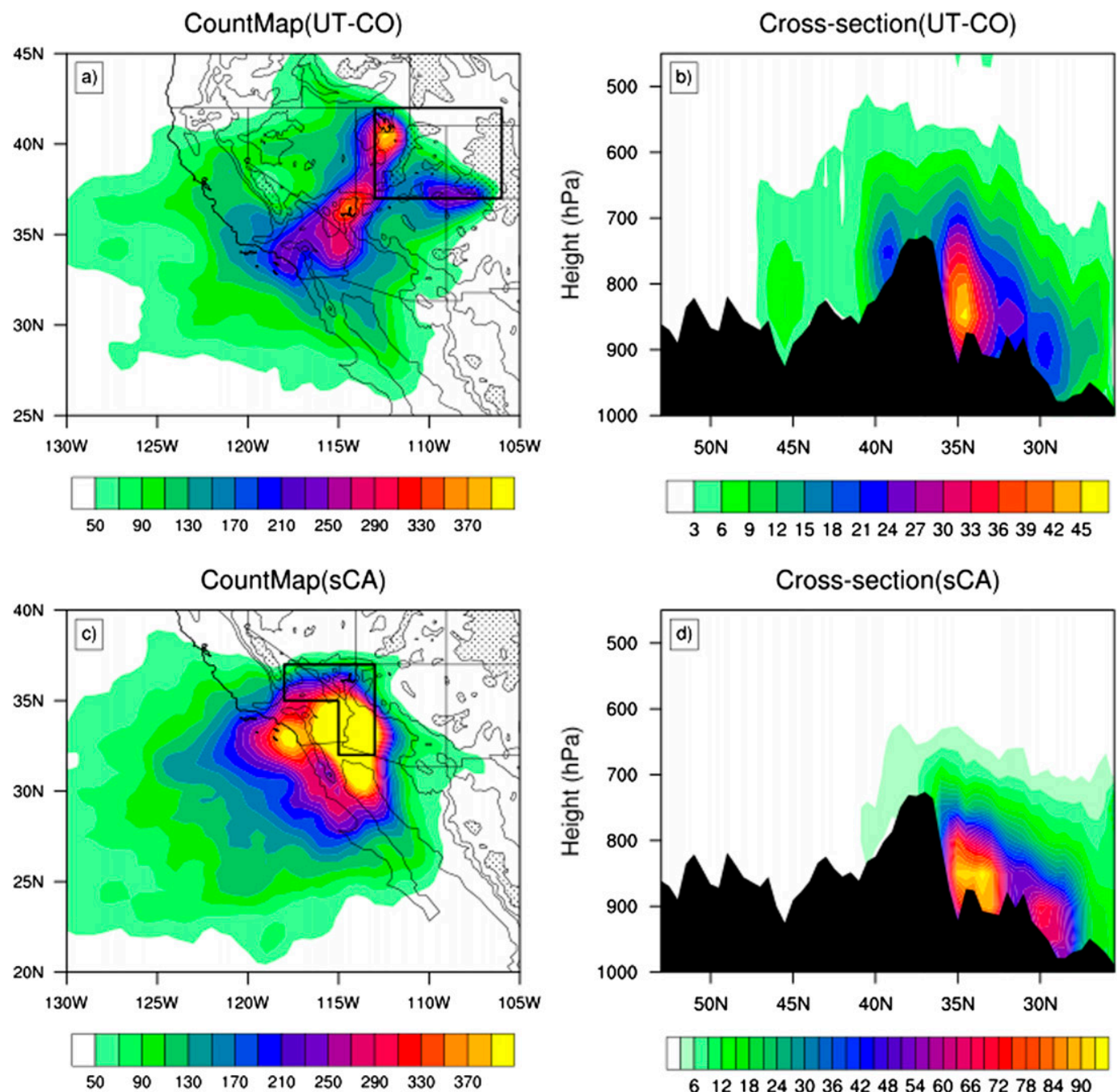

CountMap(AZ-NM)
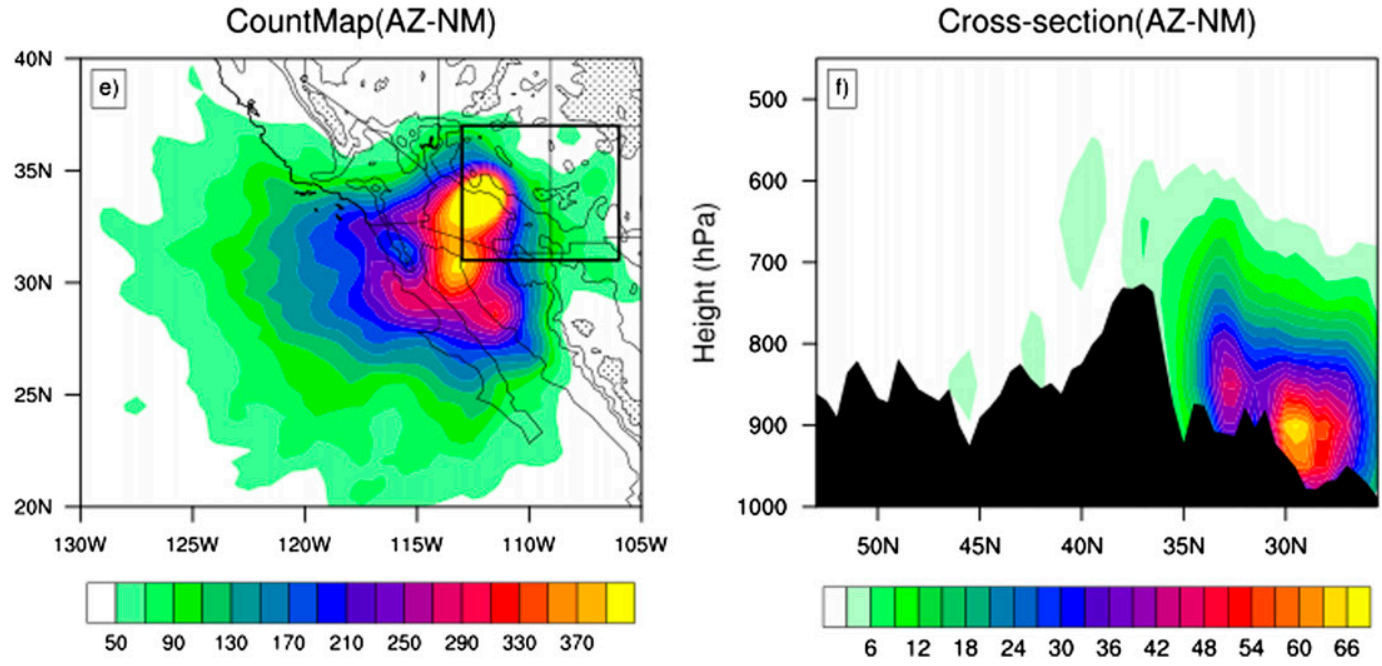

FIG. 5. As in Fig. 4, but for the (a),(b) UT-CO; (c),(d) sCA; and (e),(f) AZ-NM regions. 
generator. As in the extreme cases, trajectories were initiated at the four CFSR grid points nearest to the station and at four 6-h intervals on the randomly chosen day. This procedure was repeated 300 times based on the number of trajectories needed to obtain stable count results for the random cases; the counts were then scaled by dividing by two so they could be directly compared with the 150 extreme cases. Count maps and cross sections for the randomly generated trajectories in the northern and southern regions are shown in Figs. SM8 and SM9 in the supplemental materials, while the difference in the counts between the extreme and randomly generated trajectories are shown in Figs. 6 and 7.

The general patterns of the count maps and cross sections for the randomly generated trajectories (Figs. SM8 and SM9 in the supplemental materials) are similar to those based on the extreme cases in all six regions (Figs. 4, 5). For example, as in the extreme cases, a large fraction of the trajectories at randomly selected stations/days for the WA-nID region follow the Columbia River valley, passing through the gap in the Cascades. However, consistent differences between the two are apparent as well. The back-trajectory counts within the boundaries of all six regions are lower in the extreme compared to the random cases (Figs. 6, 7). This suggests faster movement of the air parcels, that is, fewer trajectories remain in the target region over time, and likely more moisture transport by stronger winds during winter periods with extreme precipitation. In addition, the back trajectories exhibit a more southwesterly path and are generally lower in the atmosphere in the extreme compared to the random cases. For example, in the OR-sID region (Figs. 6c,d), the number of trajectories passing through California and north of the Sierra Nevada increases and the number of trajectories through the Columbia gorge gap decreases in the extreme relative to the random cases; there are also fewer trajectories on extreme days above (at pressures less than) $700 \mathrm{hPa}$. One anticipates that air parcels originating farther north and/or at higher elevation would be cooler and carry less water vapor. This analysis suggests that, while the pathways into the interior west on days with heavy precipitation might not be unique, strong flow from the southwest at lower elevations is effective at funneling moisture through the mountain gaps.

\section{b. EOFs and PC-based composites}

The three leading EOFs of IVT are shown in Fig. 8a; recall that the EOFs are computed using normalized IVT values over land, so they are better able to depict the patterns of variability in the IMW. The dominant pattern, which explains $28.5 \%$ of the variance, has one sign over the western United States with a maximum in southern Oregon and Idaho. The second EOF, which explains $23.8 \%$ of the variance, exhibits a meridional dipole of IVT, with centers over Arizona and along the United States-Canada border, and the third EOF, which explains $9.9 \%$ of the variance, has anomalies of one sign over California and Nevada and anomalies of the opposite sign over the rest of the land points in the domain. The three leading EOFs exhibit broad spatial patterns and explain more than $60 \%$ of the variability over the western United States.

Histograms of the three leading PCs are shown in Fig. $8 \mathrm{~b}$, where the $\mathrm{PC}$ indicates the amplitude and phase of the associated EOF pattern over time. The histogram of PC1 is highly skewed toward positive values, indicating that large positive IVT anomalies into the western United States, where EOF1 exhibits maximum variance, are much more common than large negative anomalies. This is consistent with the atmospheric river concept, with a strong narrow band of water vapor transport during storms and weak/diffuse dry conditions between storms. The second and third PCs also exhibit positive skew, but not to the extent of PC1.

EOFs maximize the explained variance over the entire domain, and the patterns are required to be orthogonal in both space and time, which can result in nonphysical patterns. This is especially the case for lower-order EOFs/PCs. However, there is not a set decision criteria for determining how many EOFs are statistically significant, and the number of EOFs corresponding to physical patterns in the system may be different from this criteria (see, e.g., Hannachi et al. 2007). We examine the synoptic conditions associated with the leading EOFs using PC-based composites of the full anomaly fields but modify the compositing method (described below) to extract realistic synoptic patterns associated with EOF3/PC3.

The EOF analysis was performed using IVT anomalies during all cold season days at 6-h intervals; since we wish to focus on extreme events, composites were constructed based on when the largest-amplitude values $(>|99 \%|)$ of the three leading PCs occurred. We used the upper $1 \%$, an average of 232 cases for the 6-hourly values used here, as opposed to the top 150 cases $(\sim 2.5 \%)$ based on daily values, as done for the precipitation-based trajectory analysis. [The PC-based composites using the top $2.5 \%$ of the values (not shown) are similar to the ones presented below, albeit with weaker amplitude.] Since EOF1 covers the entire western United States and heavy precipitation is likely associated with large positive IVT PC1 values, "high" composites are constructed only for periods with large positive PC values. For EOF2/PC2, positive values are associated with strong IVT into the southwestern 
CountMap(WA-nID)

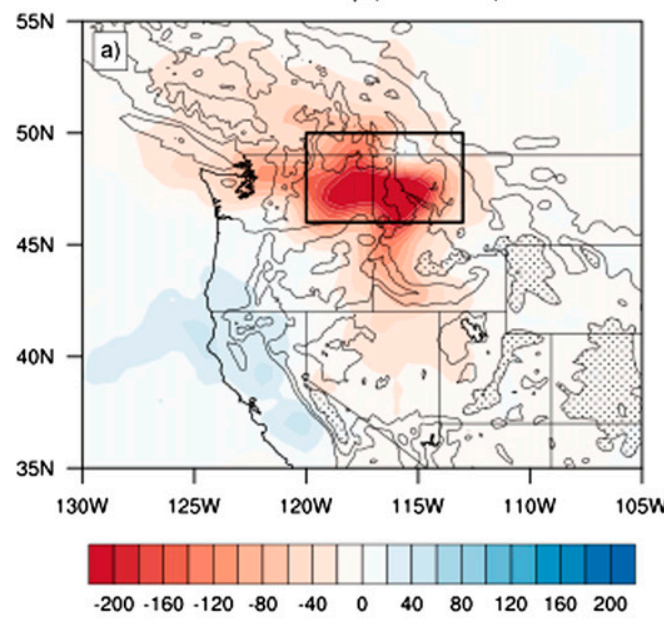

CountMap(OR-sID)

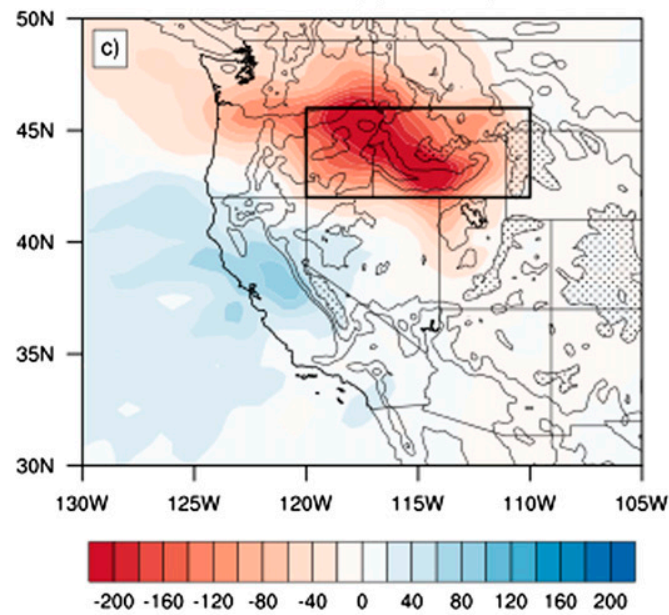

CountMap(NV)

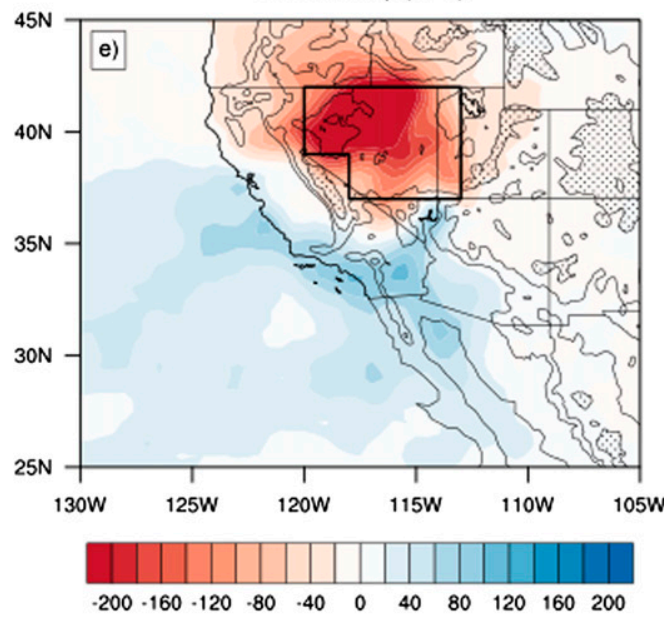

Cross-section(WA-nID)

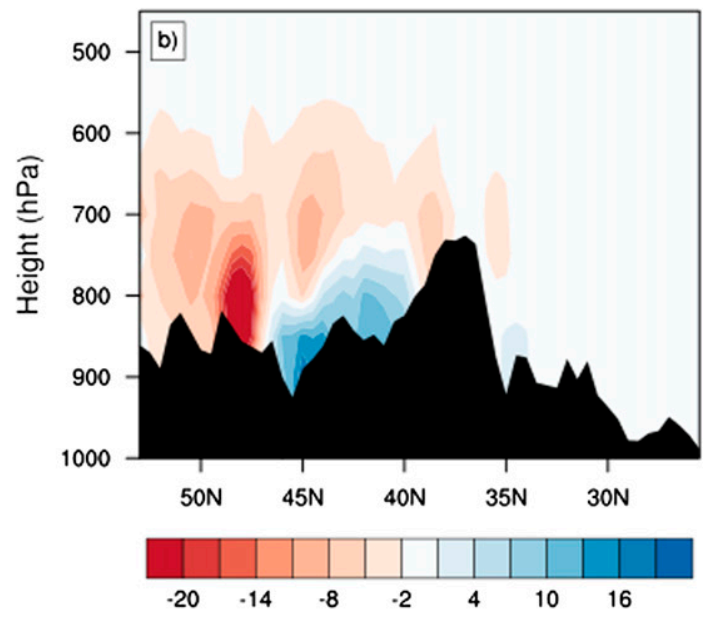

Cross-section(OR-sID)

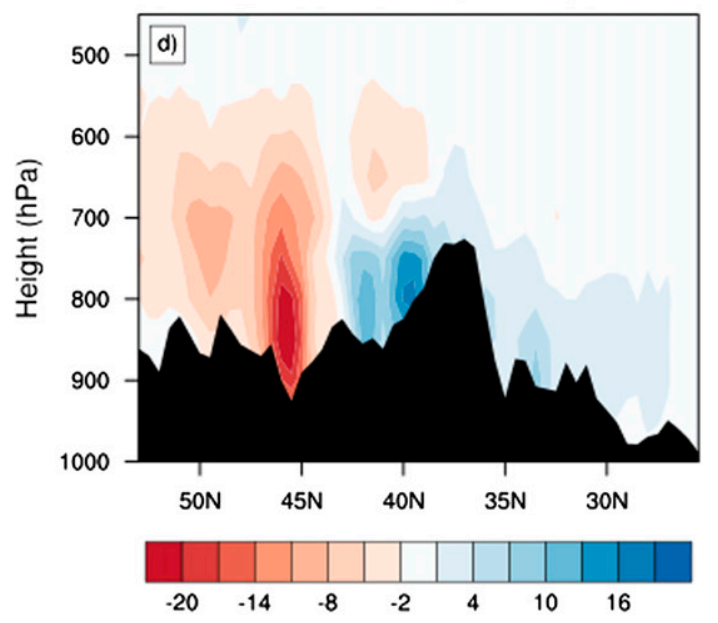

Cross-section(NV)

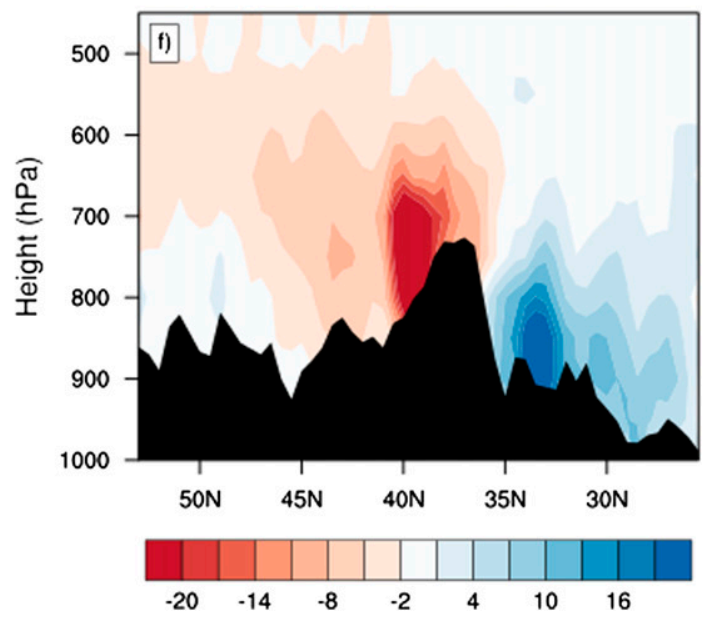

FIG. 6. (left) Count maps and (right) cross sections of the back trajectories for the top 150 days with precipitation minus 300 randomly chosen days (scaled by a factor of 0.5) over the 1979-2011 winters in the (a),(b) WA-nID; (c),(d) OR-sID; and (e),(f) NV regions. 

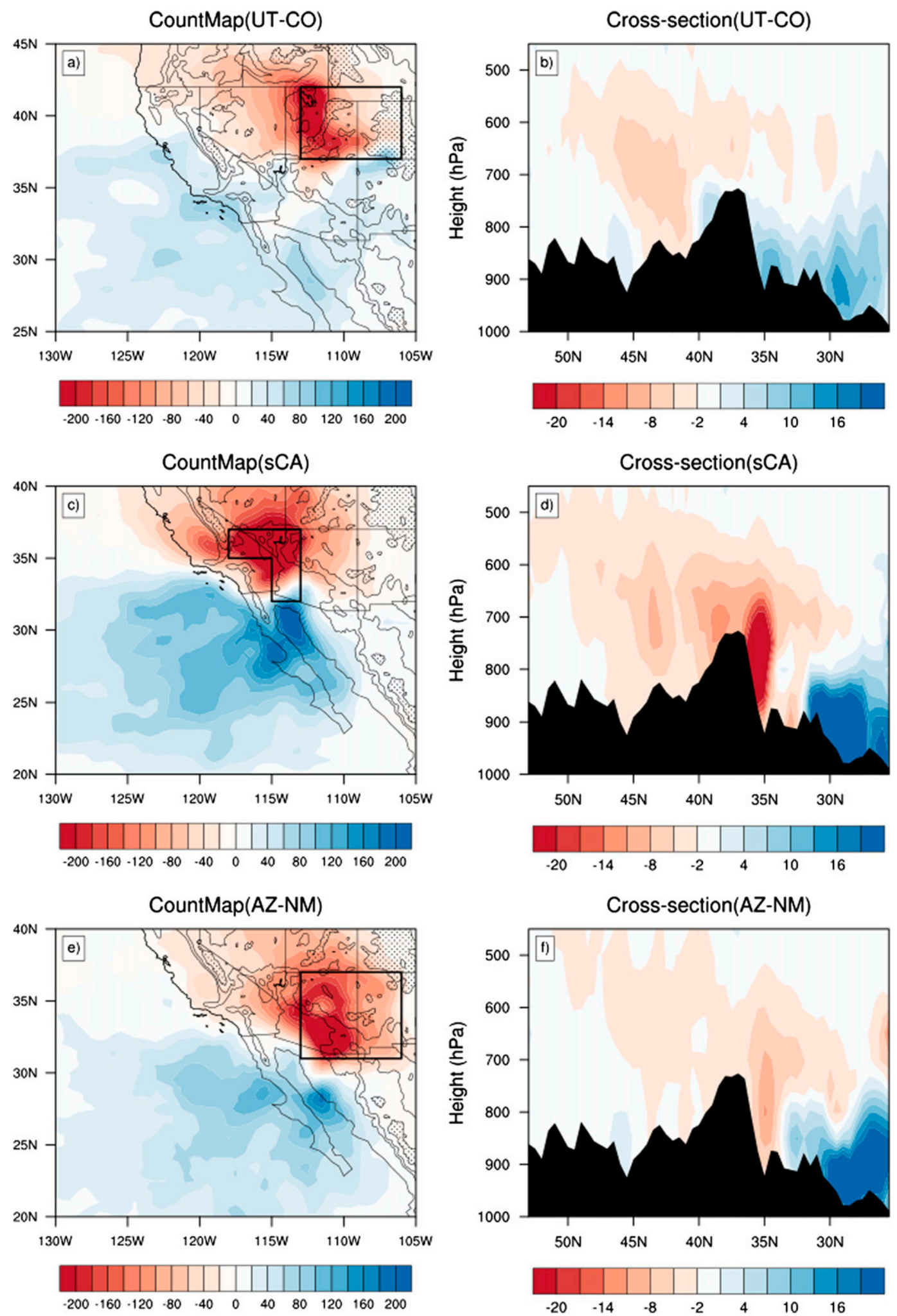

FIG. 7. As in Fig. 6, but for the (a),(b) UT-CO; (c),(d) sCA; and (e),(f) AZ-NM regions. 


\section{CFSR IVT ONDJFM 1979-2010 4xdy}
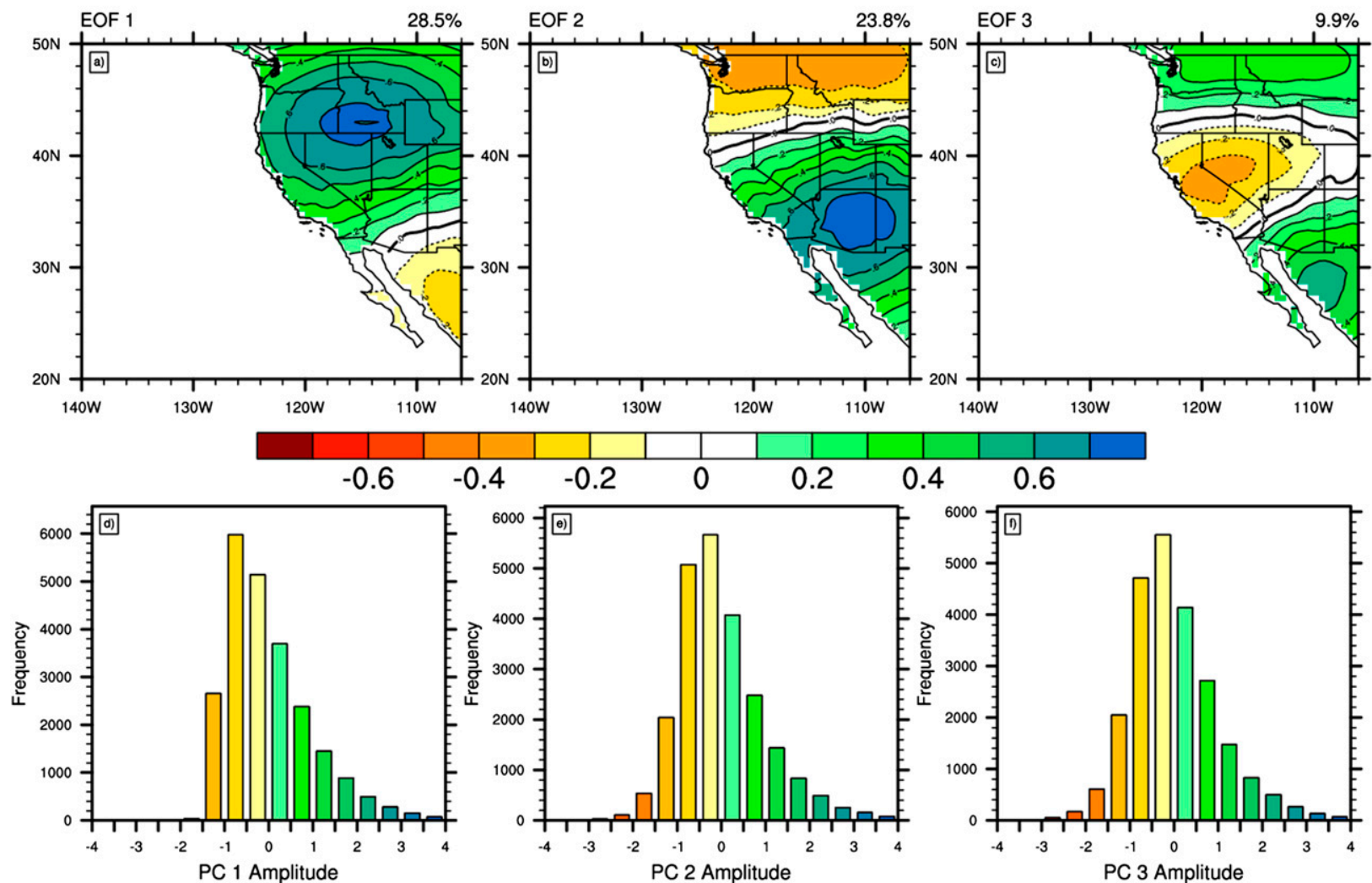

FIG. 8. (a)-(c) The three leading EOFs of the 6-hourly CFSR IVT anomalies, normalized by the local IVT monthly std dev, during October-March computed over the western United States. The anomalies are shown as a regression between the PC (time series) and the normalized anomaly. The percent of variance explained by each EOF is shown in the upper right. (d)-(f) Histograms of the three leading PC normalized values.

United States, while large negative values indicate strong transport over the northern tier states; thus, both high and low (bottom 1\%) composites are constructed for this PC. The pattern identified by EOF3 suggests the potential for strong IVT anomalies both near the southern and northern border for positive PC3 values, while negative PC3 values are associated with positive IVT anomalies in central California. Since the latter would mainly lead to precipitation in the high Sierra Nevada but not in the IMW, we will construct composites using positive PC3 values.

The synoptic conditions associated with high PC1 values are illustrated via composite maps (including values over the ocean) of the nonnormalized anomalous IVT magnitude, direction, and convergence $(-\nabla \cdot I V T)$, the specific humidity at $700 \mathrm{hPa}, 500-\mathrm{hPa}$ height, and precipitation from the CFSR and Livneh datasets. The composite IVT maps (Figs. 9a,b) show large IVT anomalies extending northwestward from the subtropical Pacific into the northwestern United States, consistent with a strong AR coming onshore in Oregon and California. Smaller-scale IVT anomalies suggest two pathways toward the interior: one through northern Oregon and into Washington, northern Idaho, and Montana and a second over central California, then extending northeastward across northern Nevada, southern Idaho, and extending into Wyoming. The water vapor anomalies (Fig. 9c) emphasize the southern of these two routes and resemble the main trajectory pathway associated with heavy precipitation events in the OR-sID region (cf. Fig. 4c). The anomalous circulation exhibits a trough centered west of Vancouver Island and a ridge over the Southwest (Fig. 9d). Both the ridge and trough exhibit a southwest-northeast tilt, with a strong gradient between them, especially over the northwestern United States. Assuming geostrophic flow, the height anomalies are consistent with the cyclonic (counterclockwise) IVT vectors west of Canada and anticyclonic (clockwise) IVT west of Baja California, with strong onshore flow of moisture into the western 


\section{CFSR IVT ONDJFM EOF 1 high $1.0 \%$ Anom Comp}
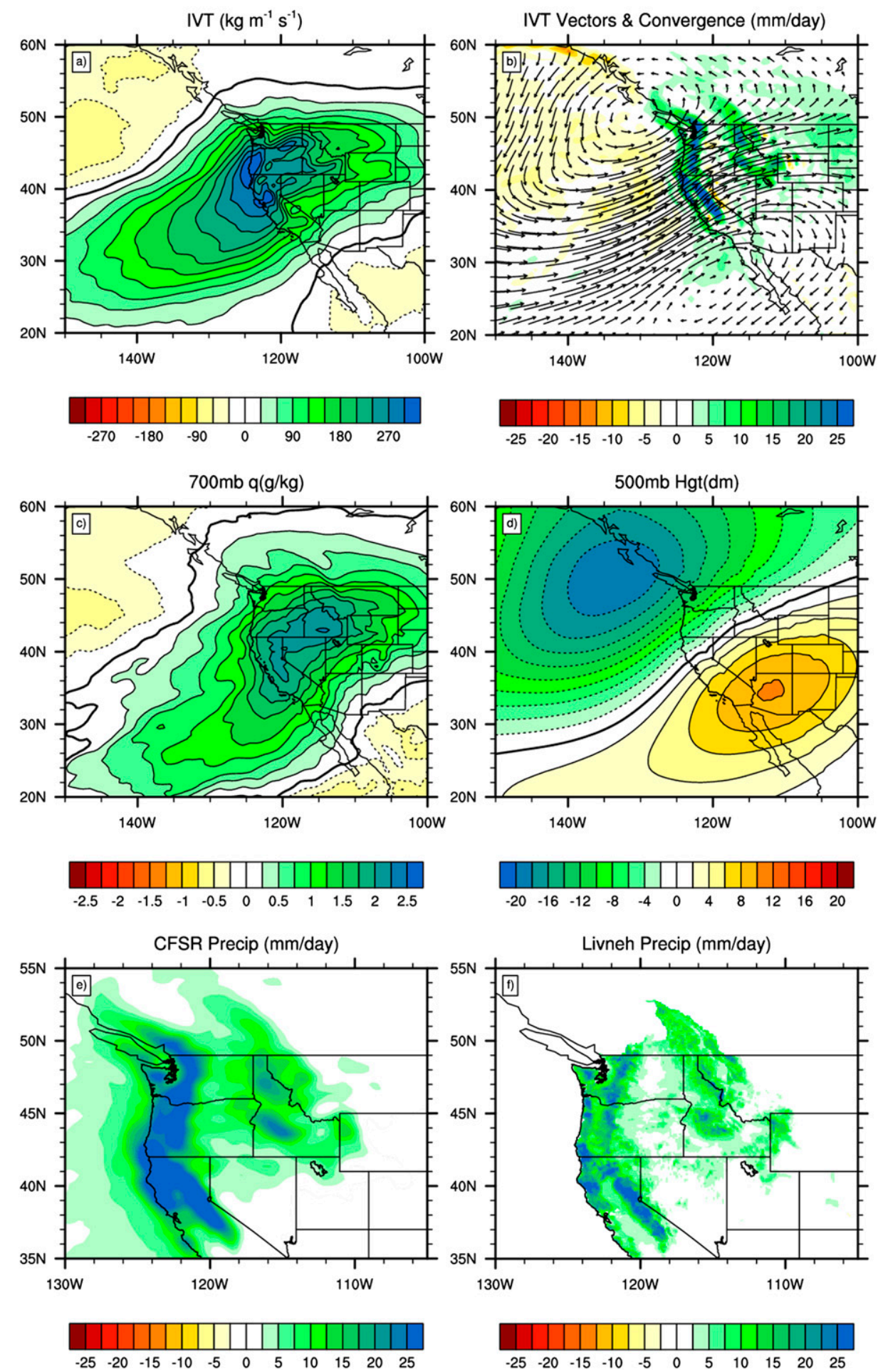

FIG. 9. High composite maps constructed from the top 1\% (232 six-hourly values) of PC1 of the anomalous (a) IVT magnitude, (b) IVT direction (vectors) and convergence-divergence ( $\mathrm{mm} \mathrm{day}^{-1}$; shading; convergence $=-\nabla \cdot$ IVT $>0$ ), (c) 700-hPa specific humidity $\left(\mathrm{g} \mathrm{kg}^{-1}\right)$, (d) 500-hPa height $(\mathrm{dm}),(\mathrm{e})$ precipitation from CFSR $\left(\mathrm{mm} \mathrm{day}^{-1}\right)$, and (f) precipitation from Livneh $\left(\mathrm{mm} \mathrm{day}^{-1}\right)$. 
United States. The anticyclonic IVT center is located west of the 500-hPa ridge because of larger mean specific humidity values over the Pacific Ocean than the western United States, so the winds transport much more water vapor onshore. Lead-lag sea level pressure (SLP) anomaly composites (Fig. SM10 in the supplemental materials) indicate that a low pressure anomaly over the northeastern Pacific intensifies and moves northeastward over 2 days before reaching a maximum near Vancouver Island (at zero lag, concurrent with the other composite fields). The SLP anomaly exhibits a more zonal structure and extends farther inland than the trough at $500 \mathrm{hPa}$.

The IVT exhibits strong convergence (Fig. 9b, green shading) over the Sierra Nevada and the Cascades from California to southern Canada and along the Coast Range in Northern California. A secondary maximum is clearly evident over mountainous regions of Idaho and western Montana. These results indicate that the moisture transport identified by IVT EOF1 does not just pass through the IMW but converges over the western mountain ranges, with corresponding weak anomalous moisture divergence on the leeward side of some mountains. While a detailed moisture budget analysis is beyond the scope of this study, the convergence of IVT $(-\nabla \cdot$ IVT $)$ is primarily balanced by precipitation minus evaporation plus the time tendency of the columnintegrated moisture [e.g., Newman et al. (2012), and references therein]. Since evaporation and the moisture tendency are generally smaller than the other budget terms during winter over the IMW (e.g., Smith and Kummerow 2013), the IVT convergence and precipitation patterns should be similar. Indeed, the composite maps of precipitation (Figs. 9e,f; note the smaller domain relative to other maps) are very similar to those of $-\boldsymbol{\nabla}$. IVT (Fig. 9b). This is consistent with the orographic driver of winter precipitation in the IMW, with moisture transported from the Pacific Ocean into the interior precipitating out when the air impinges on mountain ranges. While the broad pattern of the precipitation anomalies in the CFSR and Livneh datasets (Figs. 9e and 9f, respectively) are similar, finescale features are much better resolved in the high-resolution Livneh dataset and are clearly influenced by the local topography. For example, anomalous heavy precipitation associated with PC1 occurs near the peaks in the Sawtooth Range and the Salmon River Mountains in central Idaho, but the anomalies are negligible just to the south over the Snake River plain (Fig. 9f).

The PC2 high composite exhibits enhanced moisture transport from the Pacific Ocean, across Southern California and the Baja Peninsula, and into the southwestern United States (Figs. 10a,b). Within this broad region, there are two enhanced regions of IVT and 700-hPa $q$, one along the United States-Mexico border and the other across Baja California at approximately $29^{\circ}-30^{\circ} \mathrm{N}$ (Figs. 10a,c), where the topography is generally less than $800 \mathrm{~m}$, relatively low areas in the Peninsular Range. These enhanced areas of IVT transport are consistent with the major paths for trajectories that traverse Southern California and Baja California for heavy precipitation events in the three southern regions, especially SCA and AZ-NM (Fig. 4). The circulation anomalies exhibit a wave train with a large trough centered over Oregon-Northern California flanked by ridges to the northwest and southeast, with a strong gradient in the height field from Southern Californianorthern Baja California northeastwards to Wyoming. The associated SLP anomaly propagates eastward and becomes zonally elongated and centered farther east than the 500-hPa anomaly (at zero lag) along the border between Idaho, Nevada, and Utah (Fig. SM11 in the supplemental materials). The anomalous moisture flux convergence resulting from this flow is extensive (Fig. 10b), with large $-\nabla \cdot$ IVT values and heavy precipitation in the Sierra Nevada and the Peninsular Ranges in California but also in the interior, including the Mogollon Rim in Arizona, the Wasatch Range in Utah, and the San Juan Mountains in southwestern Colorado (Figs. 10e,f).

The PC2 low composite features IVT anomalies with a long fetch across the eastern Pacific extending from $\sim 25^{\circ} \mathrm{N}, 145^{\circ} \mathrm{W}$ to the Pacific Northwest, where it turns and extends eastward along the Canadian border (Figs. 11a,b). A local maximum in IVT and specific humidity extends across Washington and northern Idaho and into Montana (Figs. 11a-c), which is consistent with the trajectory path leading to heavy precipitation in the WA-nID region (Fig. 4a). The 500-hPa height pattern features a ridge centered over the IMW and a trough off the Canadian coast, which are elongated along a southwest-northeast axis (Fig. 9d). As in the previous composites, the anomalous SLP is zonally elongated with a strong gradient along its southern flank, here parallel to the United States-Canada border (Fig. SM12 in the supplemental materials). Strong IVT convergence and heavy precipitation occurs over the Olympic Mountains and the Cascade Range in western Washington and southern British Columbia, with a secondary maximum over northern Idaho and southeastern British Columbia (Figs. 11b,e,f). However, there is anomalous IVT divergence but positive precipitation anomalies in a few narrow meridional bands, such as in central Washington and western Montana extending northwest into Canada. These occur in the lee of mountains and are likely associated with subsidence and drying. This 


\section{CFSR IVT ONDJFM EOF 2 high $1.0 \%$ Anom Comp}
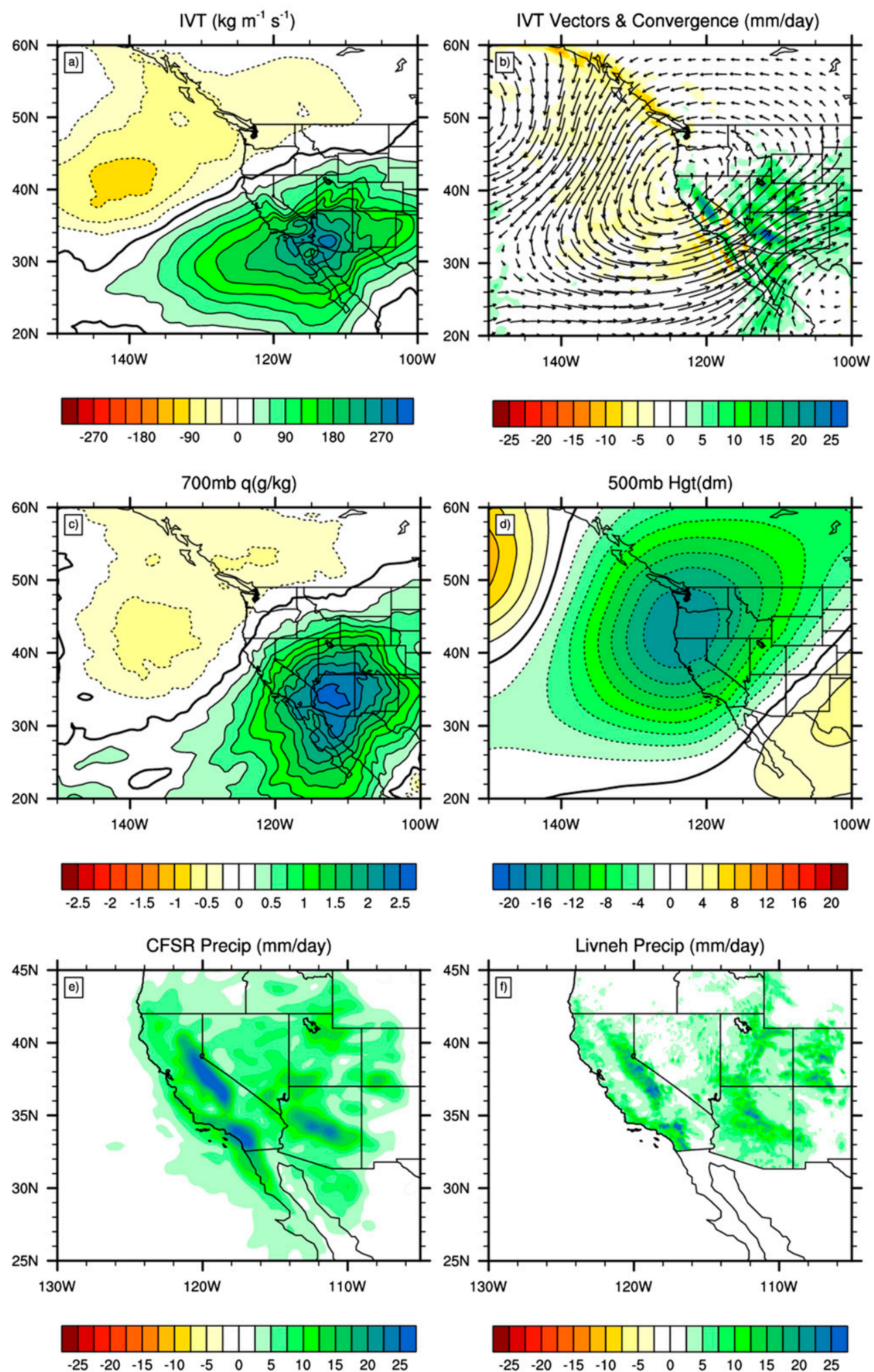

FIG. 10. As in Fig. 9, but for the high composite maps constructed from the top 1\% of PC2 values. 
CFSR IVT ONDJFM EOF 2 Low $1.0 \%$ Anom Comp
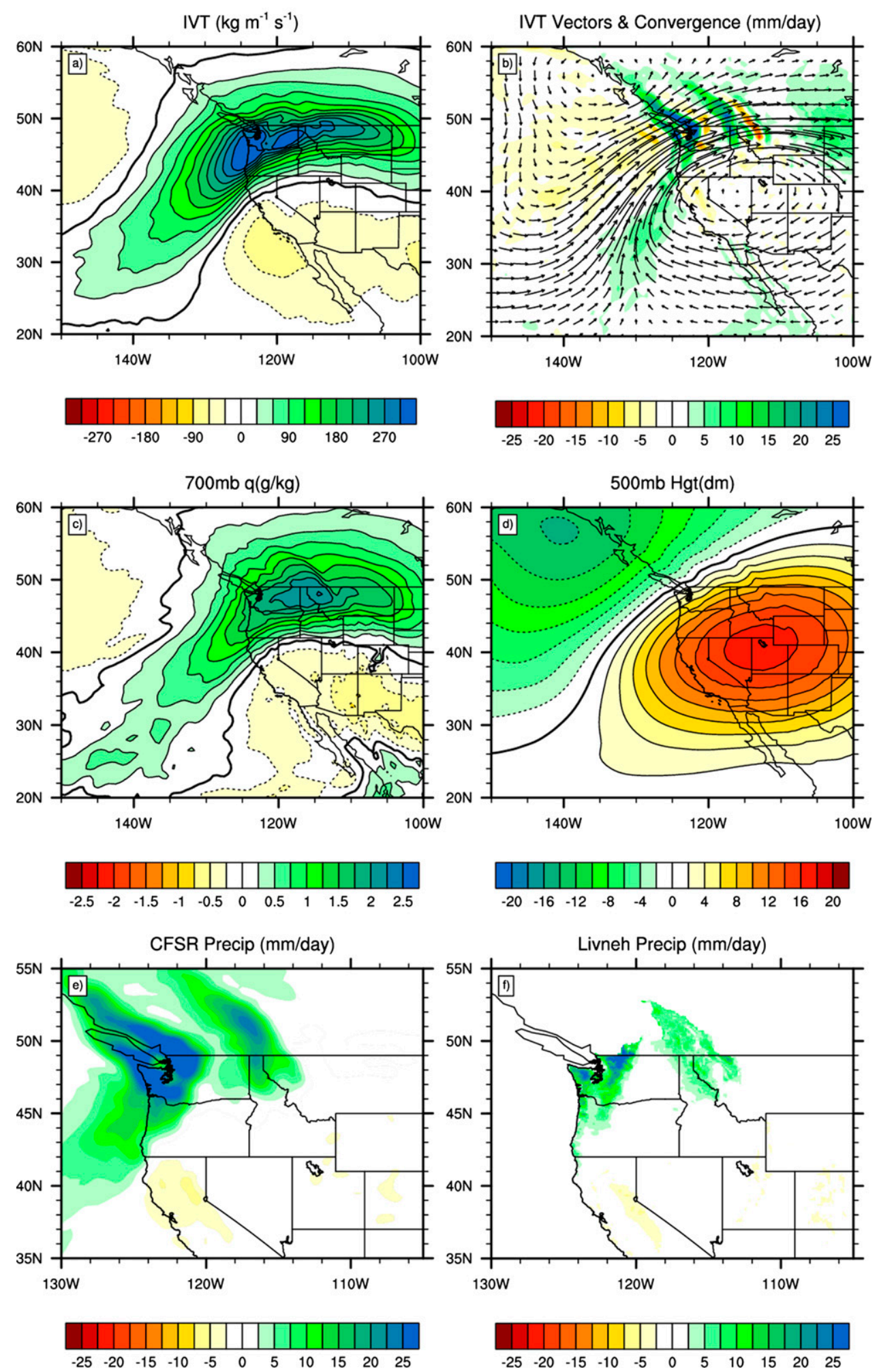

FIG. 11. As in Fig. 9, but for the low composite maps constructed from the bottom (negative) $1 \%$ of $\mathrm{PC} 2$ values. 
apparent discrepancy with enhanced precipitation in these regions may be due to several factors, including 1) enhanced evaporation compensating for the moisture divergence, 2) a nonnegligible decrease over time in the column-integrated moisture content, and 3) after assimilation of observations the moisture budget is not balanced in CFSR (or other reanalyses). Weak negative precipitation anomalies also occur over Northern California and Colorado.

To determine if EOF3 represents a coherent pattern, we first regressed out the contribution of both EOF1 and EOF2 from the full anomaly fields at each time step (the original EOF3 becomes the leading pattern of the remaining variance). We then computed the correlation between regional averages of the IVT anomalies in the northern center of this EOF (northern Washington; $48^{\circ}-$ $50^{\circ} \mathrm{N}, 120^{\circ}-118^{\circ} \mathrm{W}$ ) and the southern center (northwestern Mexico; $28^{\circ}-30^{\circ} \mathrm{N}, 111^{\circ}-109^{\circ} \mathrm{W}$ ), which have the same sign (Fig. 8). The correlation between the two regions is -0.07 for all days and -0.25 for the top $1 \%$ of the PC values. This suggests that the IVT in the two regions associated with the original EOF3/PC3 are not strongly related but are an artifact of the analysis technique. [In the full dataset, the two regions are strongly anticorrelated $(r=-0.83)$ because of the out-of-phase relationship between IVT anomalies in these two areas associated with EOF2/PC2]. The atmospheric circulation associated with the positive phase of EOF3 includes a relative small-scale "cutoff" low pressure center located just west of northern Baja California (not shown). Cutoff lows that are fairly common in the wintertime circulation can cause heavy precipitation in the southwestern United States (Knippertz and Martin 2007), and are different from the weather patterns associated with the first two EOFs.

The following procedure is used to construct composites that isolate the cutoff lows and the related IVT and circulation anomalies over the Southwest. First, based on the full anomaly fields, we identify 6-h periods with the top $1 \%$ of PC3 values. Next, we exclude periods that are in the top or bottom $1 \%$ of PC2 cases, as PC2 strongly influences IVT in the southwestern United States. Finally, we retain events where the IVT anomaly is positive in the southern center of EOF3 located over northwestern Mexico. We retain 116 cases that pass these criteria to construct a composite. The composite indicates enhanced IVT transport and specific humidity over southern Baja California, the Gulf of California, northwestern Mexico, and into southern Arizona and New Mexico (Fig. 12). While the topography in northern Mexico is relatively high, moisture may be able to move through the north-south-oriented mountain valleys of northern Mexico and over the low topography along the eastern shore of the Gulf of California. Moisture can also propagate inland from the Gulf of California into Arizona along the Colorado and Gila River valleys. The $500 \mathrm{hPa}$ (Fig. 12d) and SLP field (Fig. SM13 in the supplemental materials) exhibit a cutoff low, just west of northern Baja California with a weak trough to the north, from which the cutoff may have been linked to at a previous time. Over the United States, the precipitation exhibits a maximum over the Mogollon Rim in Arizona and western New Mexico. These circulation and precipitation anomalies closely resemble the "Type 2" AR events identified by Rivera et al. (2014). Enhanced precipitation also occurs over western Washington, likely associated with the weak trough located to the north, perhaps indicating a link between precipitation in the northwestern and southwestern United States identified in the original EOF3.

\section{Summary and discussion}

Two complementary methods were used to identify the paths that moisture takes to reach the U.S. Intermountain West (IMW) that contributes to heavy precipitation events during winter. In the first, the top 150 precipitation events at stations located within each of six regions in the IMW were identified, and then back trajectories were initiated on those days at the four CFSR grid points nearest the stations. While the trajectories track air parcels and not moisture explicitly, by initiating the parcels relatively close to the surface (within $50-100 \mathrm{hPa}$ of the SLP) where the moisture is concentrated, the trajectories should provide a reasonable representation of water vapor movement. The second method identified the leading patterns of IVT, using the three leading EOFs of IVT over land that were first normalized by the local standard deviation. The top $1 \%$ of the associated PCs were used to identify 6 -h periods in which the amplitude of the EOF patterns were large and then composites of IVT, atmospheric circulation, and precipitation were computed using those periods. To focus on regions where moisture transport was strong, composites were constructed using positive (high) values of $\mathrm{PC} 1, \mathrm{PC} 2$, and $\mathrm{PC} 3$ and negative (low) values of PC2 (with large IVT along the Canadian border); only a subset of these days were used in the PC3based composites to better isolate realistic synoptic conditions in the southwestern United States.

The results from both methods clearly indicate that moisture originating from the Pacific that produces extreme precipitation in the IMW during winter takes dominant pathways that are influenced by gaps in the Cascade Range (Oregon-Washington), the Sierra Nevada (California), and the Peninsular Ranges (from 


\section{CFSR IVT ONDJFM EOF 3 (modified) high 1.0\% Anom Comp}
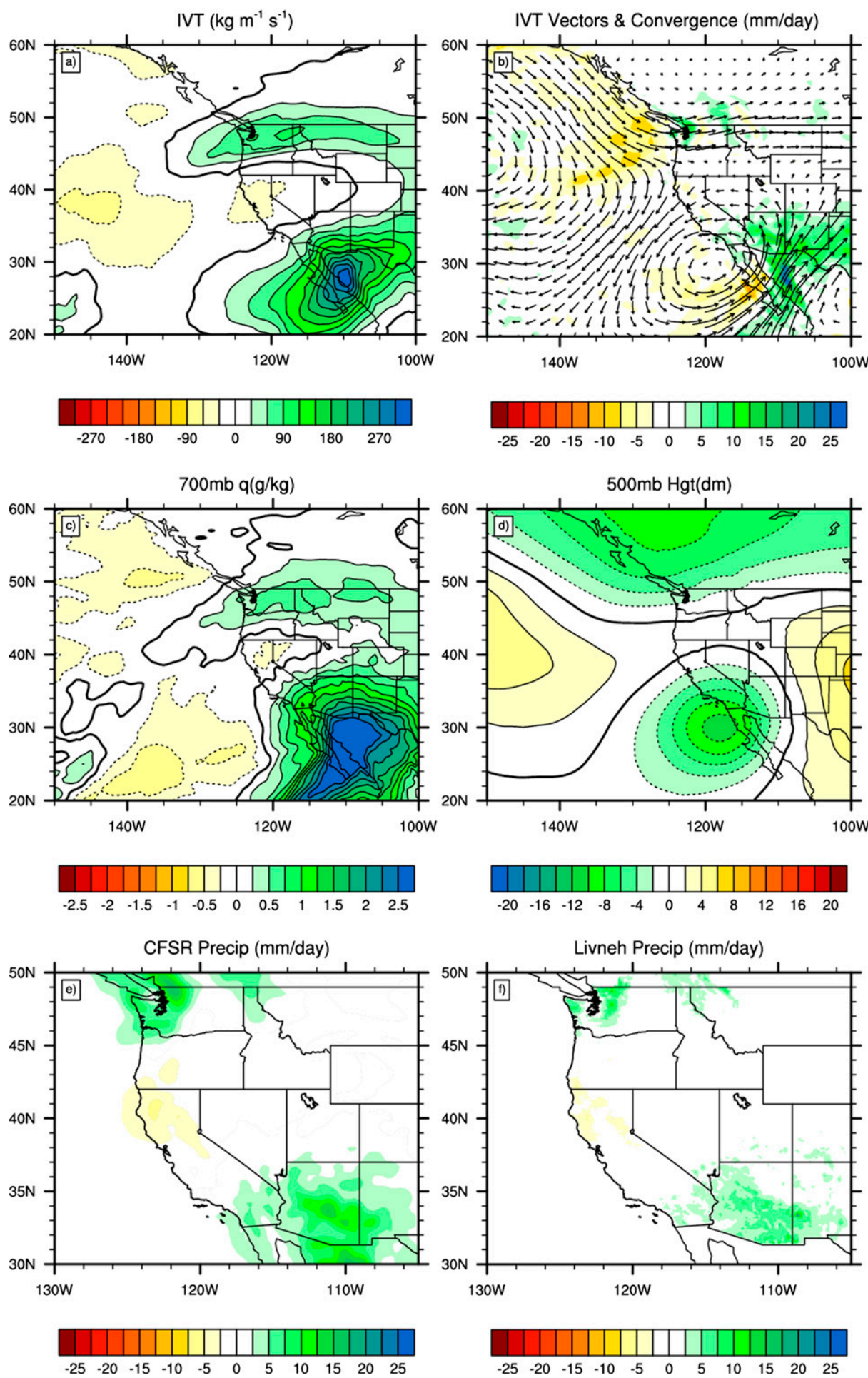

FIG. 12. As in Fig. 9, but for the high composite maps based on the top 1\% of PC3 values. To extract a realistic signal from this EOF, we also exclude periods that are in the top or bottom $1 \%$ of PC 2 cases and retain events where the IVT anomaly is positive in the southwestern United States, isolating cutoff lows, leaving 116 events in the composite. 


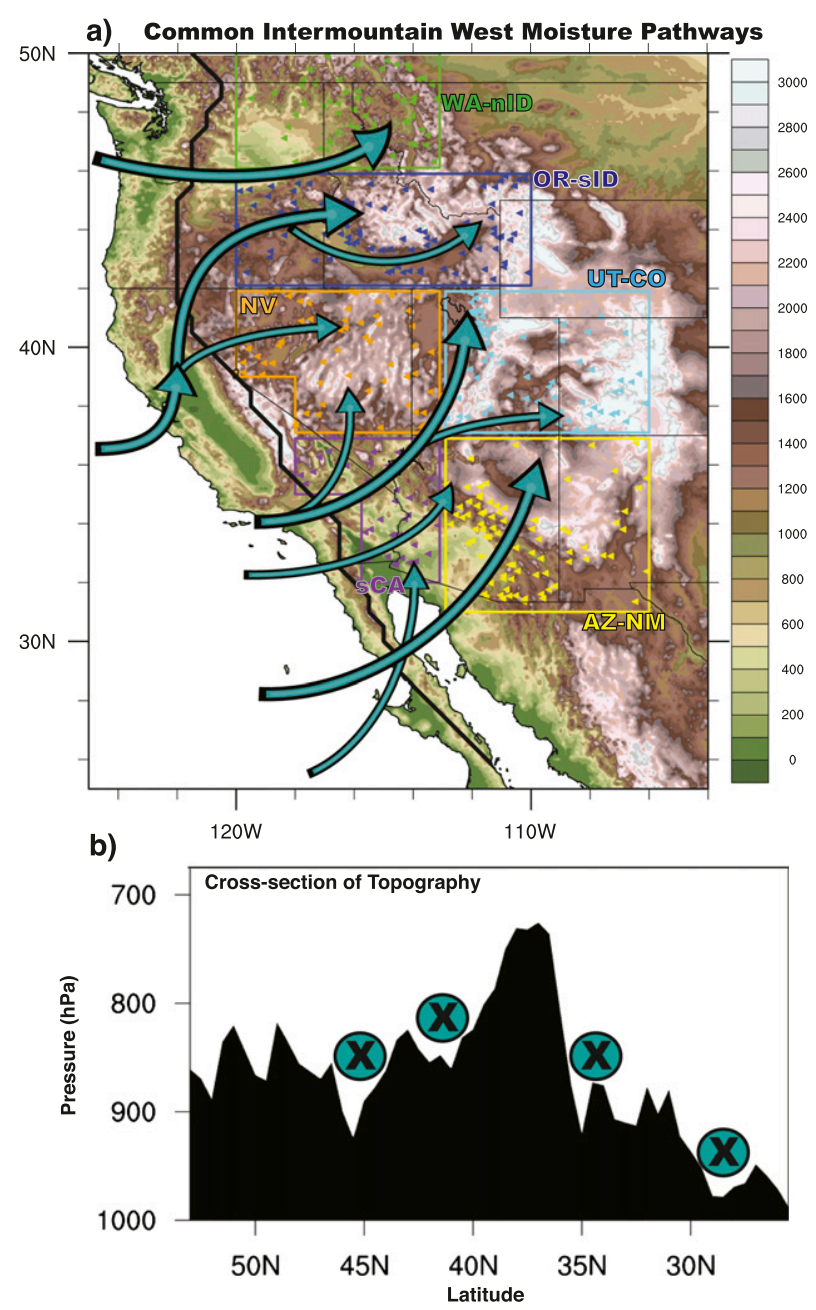

FIG. 13. (a) Schematic map and (b) cross section along the black line in (a) showing the major moisture pathways from the Pacific Ocean into the IMW.

Southern California tho Baja California). The following paths for different regions were identified (shown schematically in Fig. 13): 1) the Columbia River basin is a conduit for moisture to reach eastern Washington, northern Idaho, and western Montana; 2) a surprising path from central and Northern California, north of the high Sierra Nevada $\left(\sim 41^{\circ} \mathrm{N}\right)$, then north into eastern Oregon and Idaho, into the mountains of central Idaho and along the Snake River plain; 3) to the north and south $\left(\sim 35^{\circ} \mathrm{N}\right)$ of the high Sierra Nevada to reach Nevada; 4$)$ just south of the Sierra Nevada into portions of Utah, Colorado, and Arizona; and 5) flow centered over gaps in the Peninsular Ranges near the United StatesMexico border at $\sim 29^{\circ} \mathrm{N}$ and over the southern portion of the peninsula that has relatively low topography, bringing moisture to Arizona and western New Mexico. These pathways are consistent with recent studies of the penetration of atmospheric rivers into the IMW; that is, Rutz and Steenburgh (2012) found that the high Sierra Nevada strongly block the inland penetration of ARs, while Neiman et al. (2013), Hughes et al. (2014), Rivera et al. (2014), and Rutz et al. (2014) found that water vapor transport leading to heavy precipitation in the Mogollon Rim passes through low points in the mountains of Baja California. The moisture transported along these routes appears to be the primary source for heavy precipitation for the mountain ranges in the IMW, including the Bitterroot Mountains in northern Idaho, the Salmon River Mountains and the Sawtooth Range in south-central Idaho, the Wasatch Range in Utah, the San Juan Mountains in southwestern Colorado, and the Mogollon Rim in Arizona.

Several factors may influence the moisture pathways identified here. There can be two (or more) pathways to a given region, for example, air parcels can reach the WA-nID region from California via the mountain gap to the north of the Sierra Nevada, in addition to the main pathway along the Columbia River valley. A single pathway can also transverse more than one region; for example, water vapor transport through the gap south of the Sierra Nevada can result in heavy precipitation in southeastern California (sCA), eastern Nevada (NV), the Mogollon Rim (UT-NM), and the Wasatch Range and San Juan Mountains in southwestern Colorado (UT-CO). Also, the station locations, which are usually located in valleys, likely miss extreme precipitation events at higher elevations and thus the associated pathways. For example, the trajectory analysis did not clearly identify the path that leads to heavy precipitation in the mountains of northern Colorado, such as the Gore or Park Ranges (near $\sim 40^{\circ} \mathrm{N}, 106.5^{\circ} \mathrm{W}$ ). Thus, a more quantitative method for identifying regions (e.g., Bernard et al. 2013), including precipitation estimates from higher elevations and using finer-resolution datasets that better resolve gaps through the complex topography, may lead to a more precise depiction of the moisture pathways in the IMW.

The seasonal cycle, including changes over the course of the cold season, could impact the moisture transport into the IMW. We briefly investigated the seasonal cycle impact on moisture transport over the winter months using two different EOF analyses of 6-h IVT. First, we examined the variability of the PC values associated with the three leading PCs during the months of October-March. The amplitude of the standard deviation and the 95th percentile values are similar for each of the three PCs during all 6 months, with midwinter values (December-February) being somewhat stronger $(10 \%-20 \%)$ than in early winter for EOF1 and EOF2, while EOF3 values are slightly (5\%-10\%) 
stronger in November and December (Fig. SM14 in the supplemental materials). Second, the EOFs were calculated using 2-month periods: October-November, December-January, and February-March. The EOF patterns and percent variance explained (Fig. SM15 in the supplemental materials) and standard deviation of the PC values (not shown) are all very similar to each other and the EOFs obtained from the full OctoberMarch period (Fig. 8a). These analyses suggest that the patterns of moisture transport do not vary greatly over the course of the winter, but this preliminary finding should be examined in much greater detail.

While the topography clearly influences the moisture transport and precipitation in the IMW, it is the largescale atmospheric circulation and synoptic conditions that ultimately shape the conditions necessary for heavy precipitation to occur. For example, under some conditions, the flux of warm, moist air may be strong enough so that not all of the moisture precipitates over the Cascade Range and can thereby reach eastern Oregon and Idaho (see Figs. 4, 7). In addition, the pathways identified here are not limited to moist air (Figs. SM8 and SM9 in the supplemental materials). Air also flows through these gaps from the west during dry conditions, albeit more from the north and at higher elevations; for example, trajectories reaching the OR-sID region often pass over the Columbia River gap.

The general synoptic conditions associated with heavy precipitation events in the IMW include a trough-ridge couplet at $500 \mathrm{hPa}$, with the trough located northwest of the ridge and a tight gradient between them over and upstream of where the heavy precipitation occurs. The accompanying circulation results in strong moisture transport from the southwest that reaches a maximum near the topographic gaps. While our analyses are based on precipitation and IVT over the western United States, the general circulation features are consistent with studies of ARs that impact the Pacific coast and feature concentrated moisture transport ahead of a cold front that extends thousands of kilometers southwestward over the Pacific Ocean. In addition to the largescale ridge-trough system in midlatitudes, smaller-scale cutoff lows, which move onshore at $\sim 30^{\circ} \mathrm{N}$, can also transport tropical moisture across southern Baja and the Gulf of California, resulting in heavy precipitation over central Arizona [also see Knippertz and Martin (2007) and Rivera et al. (2014)].

Determining potential pathways and sources for extreme precipitation events may help inform decisions about dam safety, flood hydrology, and future monitoring. The trajectory and EOF/composite analyses performed here could also provide useful indicators for short-term (1-2 day) predictions at dam sites and indicate the attributes of winter storms that generate the heaviest precipitation in a given region. The impact of lower-frequency climate phenomena, such as ENSO, on the moisture transport and pathways warrants further study.

Acknowledgments. We acknowledge the Bureau of Reclamation for their intellectual and financial support for this project, and in particular thank Levi Brekke, Jason Caldwell, John England, and Victoria Sankovitch. Joseph Barsugli provided helpful suggestions during the course of the project. We also thank Ian Simmonds from the University of Melbourne for providing the trajectory software and Ben Livneh at the University of Colorado Boulder for providing the gridded precipitation data.

\section{REFERENCES}

Bao, J.-W., S. A. Michelson, P. J. Neiman, F. M. Ralph, and J. M. Wilczak, 2006: Interpretation of enhanced integrated water vapor bands associated with extratropical cyclones: Their formation and connection to tropical water vapor. Mon. Wea. Rev., 134, 1063-1080, doi:10.1175/MWR3123.1.

Barras, V., and I. Simmonds, 2009: Observation and modeling of stable water isotopes as diagnostics of rainfall dynamics over southeastern Australia. J. Geophys. Res., 114, D23308, doi:10.1029/2009JD012132.

Bernard, E., P. Naveau, M. Vrac, and O. Mestre, 2013: Clustering of maxima: Spatial dependencies among heavy rainfall in France. J. Climate, 26, 7929-7937, doi:10.1175/JCLI-D-12-00836.1.

Bernhardt, D., 2006: Glacier National Park flooding November 2006. NWS Western Region Tech. Attachment 08-23, 15 pp.

Daly, C., R. P. Neilson, and D. L. Phillips, 1994: A statisticaltopographic model for mapping climatological precipitation over mountainous terrain. J. Appl. Meteor., 33, 140-158, doi:10.1175/1520-0450(1994)033<0140:ASTMFM>2.0.CO;2.

Dettinger, M. D., F. M. Ralph, T. Das, P. J. Neiman, and D. Cayan, 2011: Atmospheric rivers, floods, and the water resources of California. Water, 3, 445-478, doi:10.3390/w3020445.

Durre, I., M. J. Menne, and R. S. Vose, 2008: Strategies for evaluating quality assurance procedures. J. Appl. Meteor. Climatol., 47, 1785-1791, doi:10.1175/2007JAMC1706.1.

,-- B. E. Gleason, T. G. Houston, and R. S. Vose, 2010: Comprehensive automated quality assurance of daily surface observations. J. Appl. Meteor. Climatol., 49, 1615-1633, doi:10.1175/2010JAMC2375.1.

Fuhrmann, C. M., and C. E. Konrad, 2013: A trajectory approach to analyzing the ingredients associated with heavy winter storms in central North Carolina. Wea. Forecasting, 28, 647-667, doi:10.1175/WAF-D-12-00079.1.

Gaberšek, S., and D. R. Durran, 2006: Gap flows through idealized topography. Part II: Effects of rotation and surface friction. J. Atmos. Sci., 63, 2720-2739, doi:10.1175/JAS3786.1.

Hannachi, A., I. T. Jolliffe, and D. B. Stephenson, 2007: Empirical orthogonal functions and related techniques in atmospheric science: A review. Int. J. Climatol., 27, 1119-1152, doi:10.1002/joc.1499.

Hughes, M., K. M. Mahoney, P. J. Neiman, B. J. Moore, M. Alexander, and F. M. Ralph, 2014: The landfall and inland penetration of a flood-producing atmospheric river in 
Arizona. Part II: Sensitivity of modeled precipitation to terrain height and atmospheric river orientation. J. Hydrometeor., 15, 1954-1974, doi:10.1175/JHM-D-13-0176.1.

Knippertz, P., and J. E. Martin, 2007: A Pacific moisture conveyor belt and its relationship to a significant precipitation event in the semiarid southwestern United States. Wea. Forecasting, 22, 125-144, doi:10.1175/WAF963.1.

_- and H. Wernli, 2010: A Lagrangian climatology of tropical moisture exports to the Northern Hemispheric extratropics. J. Climate, 23, 987-1003, doi:10.1175/2009JCLI3333.1.

Konrad, C. E., 1994: Moisture trajectories associated with heavy rainfall in the Appalachian region of the United States. Phys. Geogr., 15, 227-248, doi:10.1080/02723646.1994.10642514.

Lackmann, G. M., and J. R. Gyakum, 1999: Heavy cold-season precipitation in the northwestern United States: Synoptic climatology and an analysis of the flood of 17-18 January 1986. Wea. Forecasting, 14, 687-700, doi:10.1175/ 1520-0434(1999)014<0687:HCSPIT>2.0.CO;2.

Leung, L. R., and Y. Qian, 2009: Atmospheric rivers induced heavy precipitation and flooding in the western US simulated by the WRF regional climate model. Geophys. Res. Lett., 36, L03820, doi:10.1029/2008GL036445.

Livneh, B., E. A. Rosenberg, C. Lin, B. Nijssen, V. Mishra, K. M. Andreadis, E. P. Maurer, and D. P. Lettenmaier, 2013: A long-term hydrologically based dataset of land surface fluxes and states for the conterminous United States: Update and extensions. J. Climate, 26, 9384-9392, doi:10.1175/JCLI-D-12-00508.1.

Marwitz, J. D., 1980: Winter storms over the San Juan Mountains. Part I: Dynamical processes. J. Appl. Meteor., 19, 913-926, doi:10.1175/1520-0450(1980)019<0913:WSOTSJ >2.0.CO;2.

Maurer, E. P., A. W. Wood, J. C. Adam, D. P. Lettenmaier, and B. Nijssen, 2002: A long-term hydrologically based dataset of land surface fluxes and states for the conterminous United States. J. Climate, 15, 3237-3251, doi:10.1175/ 1520-0442(2002)015<3237:ALTHBD>2.0.CO;2.

McGuirk, J. P., A. H. Thompson, and N. R. Smith, 1987: Moisture bursts over the tropical Pacific Ocean. Mon. Wea. Rev., 115, 787798, doi:10.1175/1520-0493(1987)115<0787:MBOTTP>2.0.CO;2.

- — - and J. R. Schaefer, 1988: An eastern Pacific tropical plume. Mon. Wea. Rev., 116, 2505-2521, doi:10.1175/1520-0493(1988)116<2505:AEPTP > 2.0.CO;2.

Menne, M. J., I. Durre, R. S. Vose, B. E. Gleason, and T. G. Houston, 2012: An overview of the Global Historical Climatology Network-Daily Database. J. Atmos. Oceanic Technol., 29, 897-910, doi:10.1175/JTECH-D-11-00103.1.

Neiman, P. J., F. M. Ralph, A. B. White, D. E. Kingsmill, and P. O. G. Persson, 2002: The statistical relationship between upslope flow and rainfall in California's coastal mountains: Observations during CALJET. Mon. Wea. Rev., 130, 1468-1492, doi:10.1175/1520-0493(2002)130<1468:TSRBUF $>2.0 . C O ; 2$.

,-- , G. A. Wick, J. D. Lundquist, and M. D. Dettinger, 2008: Meteorological characteristics and overland precipitation impacts of atmospheric rivers affecting the west coast of North America based on eight years of SSM/I satellite observations. J. Hydrometeor., 9, 22-47, doi:10.1175/2007JHM855.1.

_ L. J. Schick, F. M. Ralph, M. Hughes, and G. A. Wick, 2011: Flooding in western Washington: The connection to atmospheric rivers. J. Hydrometeor., 12, 1337-1358, doi:10.1175/2011JHM1358.1.

_ , F. M. Ralph, B. J. Moore, M. Hughes, K. M. Mahoney, J. M. Cordeira, and M. D. Dettinger, 2013: The landfall and inland penetration of a flood-producing atmospheric river in Arizona. Part I: Observed synoptic-scale, orographic, and hydrometeorological characteristics. J. Hydrometeor., 14, 460-484, doi:10.1175/JHM-D-12-0101.1.

Newell, R. E., N. E. Newell, and C. Scott, 1992: Tropospheric rivers? A pilot study. Geophys. Res. Lett., 19, 2401-2404, doi:10.1029/92GL02916.

Newman, M., G. N. Kiladis, K. M. Weickmann, F. M. Ralph, and P. D. Sardeshmukh, 2012: Relative contributions of synoptic and low-frequency eddies to time-mean atmospheric moisture transport, including the role of atmospheric rivers. J. Climate, 25, 7341-7361, doi:10.1175/ JCLI-D-11-00665.1.

Noone, D., and I. Simmonds, 1999: A three-dimensional spherical trajectory algorithm. Research activities in atmospheric and oceanic modelling, Rep. 28, WMO/TD-942, H. Ritchie, Ed., World Meteorological Organization, 3.26-3.27.

O'Hara, B. F., M. L. Kaplan, and S. J. Underwood, 2009: Synoptic climatological analyses of extreme snowfalls in the Sierra Nevada. Wea. Forecasting, 24, 1610-1624, doi:10.1175/2009WAF2222249.1.

Pandey, G. R., D. R. Cayan, and K. P. Georgakakos, 1999: Precipitation structure in the Sierra Nevada of California during winter. J. Geophys. Res., 104, 12019-12030, doi:10.1029/1999JD900103.

Perry, L. B., C. E. Konrad, and T. W. Schmidlin, 2007: Antecedent upstream air trajectories associated with northwest flow snowfall in the southern Appalachians. Wea. Forecasting, 22, 334-352, doi:10.1175/WAF978.1.

Ralph, F. M., and M. D. Dettinger, 2011: Storms, floods and the science of atmospheric rivers. Eos, Trans. Amer. Geophys. Union, 92, 265-266, doi:10.1029/2011EO320001.

—, P. J. Neiman, and G. A. Wick, 2004: Satellite and CALJET aircraft observations of atmospheric rivers over the eastern North Pacific Ocean during the winter of 1997/98. Mon. Wea. Rev., 132, 1721-1745, doi:10.1175/1520-0493(2004)132<1721: $\mathrm{SACAOO}>2.0 . \mathrm{CO} ; 2$.

,,,--- S. I. Gutman, M. D. Dettinger, D. R. Cayan, and A. B. White, 2006: Flooding on California's Russian River: Role of atmospheric rivers. Geophys. Res. Lett., 33, L13801, doi:10.1029/2006GL026689.

Rivera, E. R., F. Dominguez, and C. L. Castro, 2014: Atmospheric rivers and extreme cool season precipitation events in the Verde River basin of Arizona. J. Hydrometeor., 15, 813-829, doi:10.1175/JHM-D-12-0189.1.

Roberge, A., J. R. Gyakum, and E. H. Atallah, 2009: Analysis of intense poleward water vapor transports into high latitudes of western North America. Wea. Forecasting, 24, 1732-1747, doi:10.1175/2009WAF2222198.1.

Rutz, J. J., and W. J. Steenburgh, 2012: Quantifying the role of atmospheric rivers in the interior western United States. Atmos. Sci. Lett., 13, 257-261, doi:10.1002/asl.392.

, ——, and F. M. Ralph, 2014: Climatological characteristics of atmospheric rivers and their inland penetration over the western United States. Mon. Wea. Rev., 142, 905-921, doi:10.1175/MWR-D-13-00168.1.

Saha, S., and Coauthors, 2010: The NCEP Climate Forecast System Reanalysis. Bull. Amer. Meteor. Soc., 91, 1015-1057, doi:10.1175/2010BAMS3001.1.

Schultz, D. M., and Coauthors, 2002: Understanding Utah winter storms: The Intermountain Precipitation Experiment. Bull. Amer. Meteor. Soc., 83, 189-210, doi:10.1175/ 1520-0477(2002)083<0189:UUWSTI >2.3.CO;2. 
Smith, R. A., and C. D. Kummerow, 2013: A comparison of in situ, reanalysis, and satellite water budgets over the upper Colorado River basin. J. Hydrometeor., 14, 888-905, doi:10.1175/JHM-D-12-0119.1.

Steenburgh, W. J., 2003: One hundred inches in one hundred hours: Evolution of a Wasatch Mountain winter storm cycle. Wea. Forecasting, 18, 1018-1036, doi:10.1175/1520-0434(2003)018<1018: $\mathrm{OHIIOH}>2.0 . \mathrm{CO} ; 2$.
_ S. F. Halvorson, and D. J. Onton, 2000: Climatology of lake-effect snowstorms of the Great Salt Lake. Mon. Wea. Rev., 128, 709-727, doi:10.1175/1520-0493(2000)128<0709: COLESO $>2.0 . \mathrm{CO} ; 2$.

Zhu, Y., and R. E. Newell, 1998: A proposed algorithm for moisture fluxes from atmospheric rivers. Mon. Wea. Rev., 126, 725-735, doi:10.1175/1520-0493(1998)126<0725: APAFMF $>2.0 . C O ; 2$. 